Working Paper/Document de travail 2012-24

\title{
Why Do Shoppers Use Cash? Evidence from Shopping Diary Data
}

by Naoki Wakamori and Angelika Welte 
Bank of Canada Working Paper 2012-24

July 2012

\title{
Why Do Shoppers Use Cash? Evidence from Shopping Diary Data
}

\author{
by \\ Naoki Wakamori and Angelika Welte \\ Currency Department \\ Bank of Canada \\ Ottawa, Ontario, Canada K1A 0G9 \\ nwakamo@gmail.com \\ wela@bankofcanada.ca
}

Bank of Canada working papers are theoretical or empirical works-in-progress on subjects in economics and finance. The views expressed in this paper are those of the authors.

No responsibility for them should be attributed to the Bank of Canada. 


\section{Acknowledgements}

We are grateful to Jason Allen, Carlos Arango, Heng Chen, Ben Fung, Chun-Yu Ho, Kim P. Huynh, Randall Morck, Leonard Sabetti, Philipp Schmidt-Dengler, Katja Seim, Shouyong Shi, Gregor Sieber, Petra Todd, Ben Tomlin and Hajime Tomura for their helpful comments and discussions. We also wish to thank the participants at the 10th Annual Meeting of the International Industrial Organization Conference (IIOC) and the 2012 Bank of Canada Fellowship Learning Exchange. 


\begin{abstract}
Recent studies find that cash remains a dominant payment choice for small-value transactions despite the prevalence of alternative means of payment such as debit and credit cards. For policy makers an important question is whether consumers truly prefer using cash or merchants restrict card usage. Using the Bank of Canada's 2009 Method of Payment Survey, we estimate a generalized multinomial logit model of payment choices to extract individual heterogeneity (demand-side factors) while controlling for merchants' acceptance of cards (supply-side factors). Based on a counterfactual exercise where we assume universal card acceptance among merchants, we find that some consumers would decrease their cash usage but the magnitude of this decrease is small. Our results imply that the use of cash in small-value transactions is driven mainly by consumers' preferences.
\end{abstract}

JEL classification: G2, D1, C2

Bank classification: Bank notes; Econometric and statistical methods; Financial services

\title{
Résumé
}

Des études récentes montrent que l'argent comptant demeure un mode de paiement privilégié pour les transactions de faible montant, malgré la prévalence d'autres moyens de paiement comme les cartes de débit et de crédit. Pour les décideurs publics, il importe de savoir si les consommateurs préfèrent vraiment régler en espèces ou, plutôt, si les commerçants restreignent l'usage de ces cartes. En nous fondant sur l'Enquête de 2009 sur les modes de paiement effectuée par la Banque du Canada, nous estimons un modèle logit multinomial généralisé des choix de paiement pour extraire l'information liée à l'hétérogénéité individuelle (facteurs de demande) tout en tenant compte de l'acceptation, par les détaillants, des cartes de paiement (facteurs d'offre). À l'aide d'une simulation contrefactuelle dans laquelle nous postulons que tous les commerçants acceptent toutes les cartes de paiement, nous constatons que certains consommateurs auraient alors moins tendance à payer en liquide, mais dans une faible mesure. Nos résultats indiquent que ce sont principalement les préférences des consommateurs qui déterminent l'usage des espèces pour de petits paiements.

Classification JEL : G2, D1, C2

Classification de la Banque : Billets de banque; Méthodes économétriques et statistiques; Services financiers 


\section{Introduction}

In recent years, consumers' method of payment choice has attracted the attention of a wide range of private firms - credit-card-issuing companies, credit and debit network providers, and mobile phone companies - as well as researchers and policy makers, as new payment technologies, such as mobile payments and contactless credit cards, have been developed. Despite the emergence of these new technologies, cash retains its dominant position at the point-of-sale, in particular, for small-value transactions. This phenomenon is found all over the world. For example, recent studies on consumer micro-payments by Klee (2008) and Arango, Huynh, and Sabetti (2011) reveal that the dominant payment method in Canada and the U.S. respectively, is cash, for transactions under 25 dollars. At the same time, these authors also report that the use of credit and debit cards increases as the transaction values increase. Similar findings are also documented by Bolt, Jonker, and van Renselaar (2010) and Simon, Simith, and West (2010) for the Netherlands and Australia, respectively.

This dominance of cash usage for small-value transactions at the point-of-sale might be partially supply driven: To avoid interchange fees, merchants tend not to accept credit or debit cards for small-value transactions. ${ }^{1}$ At the same time, however, it might be demand driven: Many consumers prefer paying in cash for its ease of use and the speed of settlements. ${ }^{2}$ Such observations bring up the following question: How would consumers pay at the point-of-sale if the government regulated merchant fees of credit and debit cards to a very low level so that all merchants would be willing to accept any cards? Answering this question is challenging because it is difficult to separately identify supply-side and demand-side factors in payment choices. The distinction is, however, essential for understanding the mechanism of demand for cash and for answering various policy-oriented and/or marketing-related questions.

This paper attempts to answer these questions by estimating a model of consumers' payment choice at the point-of-sale, using unique Canadian data based on three days of shopping diaries. The data have two key features: multiple observations per sub-

\footnotetext{
${ }^{1}$ For debit cards in Canada, merchants pay a small fixed fees per transaction to network providers.

${ }^{2}$ According to Arango, Hogg, and Lee (2012), the major reasons why people use cash for small value transactions in Canada are its wide acceptance, high ease of use or speed, low handling costs, simplicity as a tool to control spending, and anonymity.
} 
ject, and "perceived" acceptance. First, since the survey keeps track of the shopping diaries at the individual level, we can observe multiple transactions for each individual with slightly different shopping contexts, in terms of shopping types and transaction values. Observing only one transaction per subject would not be enough to identify the individual-specific effect of choosing a particular method of payment. In the data, however, we can observe multiple transactions for each individual, which enables us to extract consumer heterogeneity in payment choice. Second, consumers report the methods of payment that would have been accepted at each shopping opportunity, as well as the actual method of payment used. Although this self-reported information might contain measurement error and might not be perfectly exogenous, it is still useful to limit the consumers' choice sets. These two features of the data, as a result, enable us to separate the demand-side factors from the supply-side factors.

Payment choice is modelled as a generalized multinomial logit (G-MNL) model, proposed by Fiebig, Keane, Louviere, and Wasi (2010), to capture the heterogeneity observed in the data. A close look at the data shows that consumers can be potentially categorized into four groups: (i) consumers who only use cash (cash users), (ii) consumers who use debit cards whenever they are accepted and cash otherwise (debit users), (iii) consumers who use credit cards whenever they are accepted and cash otherwise (credit users), and (iv) consumers who use all three methods of payment (mixed users). This observation suggests that some sets of consumers have strong preferences for a particular method of payment, such as credit cards or debit cards, and use them as long as these methods are accepted by merchants.

Another type of heterogeneity in payment choice is the heterogeneous thresholds, meaning that some people within the same category might choose a different payment method even though they face the same transaction values and types. For example, some credit users might want to use credit cards even for a $\$ 5$ transaction, whereas others might use credit cards only for transactions above $\$ 20$. Similarly, within the category of mixed users, their payment choice between credit and debit cards might be quite random across individuals. This type of heterogeneity should also be captured. In the G-MNL model, we can capture such heterogeneity by introducing scale coefficients - scaling up/down the utility of one particular method of payment - and random coefficients - changing substitution patterns among alternatives. 
The importance of such consumer heterogeneity in payment choices is confirmed in the estimation results. A series of estimation results shows that the parameters that govern individual heterogeneity are statistically and economically significant. Moreover, some information criteria, such as the Akaike information criterion (AIC) and the Bayesian information criterion (BIC), which show the measurement of the goodness of fit of a model, improve dramatically by including such heterogeneity.

Using the estimated model, we conduct a policy experiment where all merchants accept any payment method regardless of the transaction value. This policy experiment can be interpreted as follows: Suppose the government regulates merchant fees to a very low level so that all merchants are willing to accept credit and debit cards. In this case, every consumer could use his preferred method of payment at any merchant. Would consumers still use cash?

We demonstrate that overall cash usage would decrease by about 7.7 percentage points in terms of transaction frequency and by 7.5 percentage points in terms of transaction values, whereas the model without any individual heterogeneity predicts smaller changes in terms of both transaction frequency and values. This difference can be explained as follows: Without taking into account individual heterogeneity, homogeneous consumers would not use cards so frequently for small-value transactions. Taking into account individual heterogeneity, however, some people who truly prefer using credit and debit cards would use these cards even for small-value transactions under the counterfactual scenario, leading to the slightly larger decrease in overall cash usage. Moreover, the relatively smaller decreases in cash usage in any model can be also interpreted to mean that cash usage in small-value transactions is driven mainly by the demand side, i.e., consumers would not use cards so much, even though all merchants are willing to accept credit and debit cards.

Research on micro-payments has attracted attention from many sources: major retail stores, mobile phone companies, credit card companies, credit card network providers, commercial banks, policy makers, and central banks. Traditional payment methods - cash, and credit and debit cards - face increasing competition from newly emerging payment methods such as online payments and mobile phone payments. Because of the need to understand the substitution between these payment methods, many empirical studies, as well as some theoretical studies, attempt to reveal the sub- 
stitution between cash and credit and debit cards. ${ }^{3}$ For example, Schuh and Stavins (2010) focus on the extinction of check usage in the U.S., while Ching and Hayashi (2010), Simon, Simith, and West (2010), Arango, Huynh, and Sabetti (2011), and Sieber (2011) examine the role that credit cards' reward programs play in the method of payment choice. Rysman (2007) asks why people use only one credit card, even though they have several other credit cards. Borzekowski, Kiser, and Ahmed (2008) and Zinman (2009) study debit card usage. ${ }^{4}$ This paper contributes to this literature by studying consumers' unobserved heterogeneity in payment choices and their demand for cash, using data on perceived acceptance and multiple observations per subject.

This paper is organized as follows: Section 2 describes the data and gives some summary statistics and motivating facts for the modelling framework. In Section 3, we present the model and the estimation procedure. The estimation results and the counterfactual simulation results are presented in Section 4 . Section 5 concludes.

\section{Data and Background Information}

\subsection{The 2009 Method of Payment Survey}

Data Description and Sample Construction The data used in this study are from the 2009 Bank of Canada Method of Payment Survey. The survey consists of two parts: a survey questionnaire and a three-day diary survey instrument. ${ }^{5}$ The survey questionnaire (hereafter SQ) includes some questions about demographic information, such as age, annual income, gender, education level, marital status, employment status, and so on. Moreover, it includes information about respondents' main bank account and main credit card, which enables us to associate their payment choices with the

\footnotetext{
${ }^{3}$ Theoretical studies include the monetary theoretic approach, such as Wright and Telyukova (2008), and the two-sided market approach, such as Rochet and Tirole (2002), Rochet and Wright (2010), and Shy and Wang (2011).

${ }^{4}$ For a more comprehensive survey, see Humphrey (2010).

${ }^{5}$ Originally, there were about 6,900 respondents to the survey questionnaire, and among them about 3300 respondents proceeded to the diary survey instrument. For this study, we need both sets of information and use the respondents who finished both.
} 
number of free debit transactions per month, and credit card rewards and annual fees. ${ }^{6}$ SQ also contains some attitudinal information, such as perceptions of convenience and safety for some particular methods of payment. This study includes such attitudinal data as explanatory variables, since the importance of such attitudinal data is emphasized in Harris and Keane (1999) and Ching and Hayashi (2010).

The diary survey instrument (hereafter DSI) asks about shopping data, including the transaction value, type of transaction, the perceived accepted methods of payment, the method of payment chosen, and the major reasons for their choice, for three consecutive days. There are two strengths of these data: (1) multiple observations per subject and (2) perceived acceptance. As for the first feature, the data provide multiple shopping observations for each individual with slightly different shopping opportunities, which allows us to study the source of individual heterogeneity. Compared with other studies using transaction-level (micro) data such as Klee (2008) and Arango, Huynh, and Sabetti (2011), we can extract the individual heterogeneity more readily with this survey data. Observing multiple shopping opportunities allows us to have individualspecific effects for method of payment choice. Moreover, perceived acceptance, another feature of these data, is also a prominent aspect of this survey. When consumers give details for each transaction, they need to state what payment methods would have been accepted. Knowing this information, we can limit the choice sets for each transaction. Therefore, together with the characteristics of the multiple observations per individual, we can separate the demand-side factors from the supply-side factors.

Since the sample is not representative, we need to use a sample weight to correct the sampling bias. ${ }^{7}$ Moreover, the analysis is restricted to the subset of the original samples. ${ }^{8}$ We construct the sample by excluding consumers who have missing information regarding the perceived acceptance, demographics, and transaction value, which are key variables in this study. Moreover, in order to estimate a random effects model, we need to have at least three shopping observations per subject to identify the individual-specific effect. Thus, we also exclude the samples with fewer than three

\footnotetext{
${ }^{6}$ In Canada, about half of bank accounts offer unlimited free debit card transactions, whereas the remaining bank accounts offer only limited free or zero free debit card transactions. For the latter type of accounts, consumers need to pay some fees after exceeding the limit on free debit card transactions.

${ }^{7}$ For more details, see Arango, Huynh, and Sabetti (2011) and Arango and Welte (2012).

${ }^{8}$ For more detailed sample construction procedure, see Appendix.
} 
Figure 1: Method of Payment Choice by Transaction Value

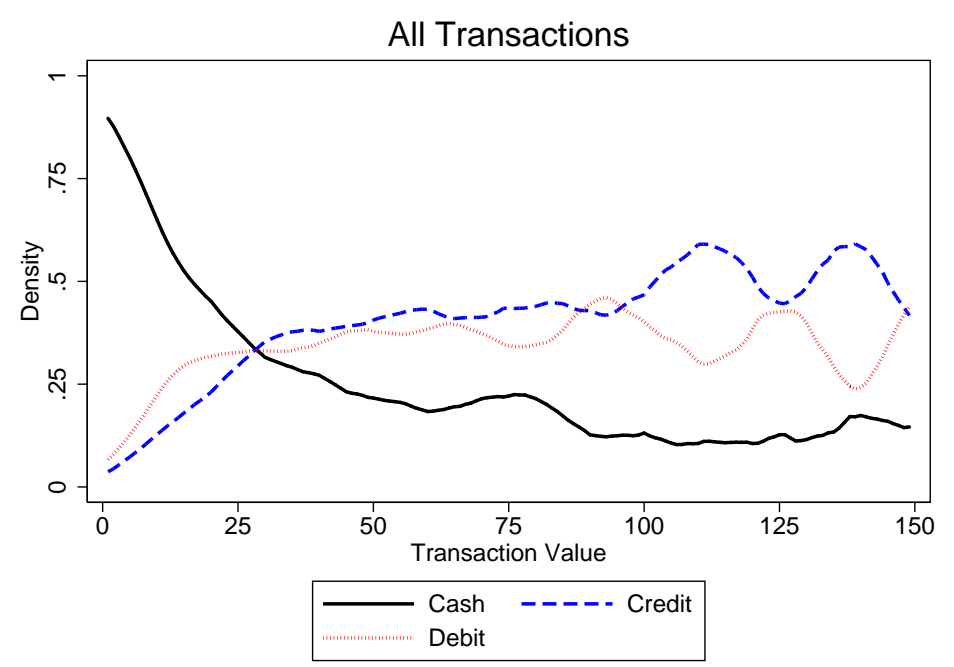

Note: This figure is based on 7,908 transactions.

shopping observations. This process leaves a total of 1,452 individuals with 7,908 transactions.

Canadian Payment Landscape Figure 1 shows the frequency of payment choice by transaction value. The black solid line, the blue dotted line, and the red dashed line show the frequency of cash, credit card and debit card usage, respectively. For example, if the transaction value is about $\$ 10$, then $60 \%, 25 \%$, and $15 \%$ of transactions are completed by cash, debit and credit cards, respectively. Notice that if the transaction value is less than $\$ 25$, cash usage dominates other payment methods, namely credit and debit cards, and this dominance is reversed as the transaction value increases, as Arango, Huynh, and Sabetti (2011) point out.

In the following subsection, we show some summary statistics and descriptive statistics to motivate why this study uses a generalized multinomial logit model, focusing on the heterogeneity in payment choices observed in the data.

\subsection{Heterogeneity in Payment Choice}

Table 1 shows how many shopping trips each individual made over the three days. The second and fifth, and the third and sixth columns display the unweighted and weighted 
TABLE 1: Histogram of the Number of Shopping Opportunities

\begin{tabular}{lrrrrrrrc}
\hline \hline & \multicolumn{3}{c}{ Before Truncation } & & \multicolumn{3}{c}{ After Truncation } \\
\cline { 2 - 5 } \cline { 7 - 8 } & Raw & Raw & Weighted & & Raw & Raw & Weighed \\
& Freq. & Percent & Percent & & Freq. & Percent & Percent \\
\hline 1 & 456 & 19.52 & 18.84 & & - & - & - \\
2 & 428 & 18.32 & 18.48 & & - & - & - \\
3 & 361 & 15.45 & 13.30 & & 361 & 24.86 & 21.21 \\
4 & 289 & 12.37 & 13.22 & & 289 & 19.90 & 21.09 \\
5 & 247 & 10.57 & 11.74 & & 247 & 17.01 & 18.73 \\
6 & 180 & 7.71 & 7.86 & & 180 & 12.40 & 12.55 \\
7 & 120 & 5.14 & 6.38 & & 120 & 8.26 & 10.08 \\
8 & 91 & 3.90 & 3.47 & & 91 & 6.27 & 5.54 \\
$9+$ & 164 & 7.02 & 6.71 & & 164 & 11.29 & 10.80 \\
\hline Total & 2,336 & 100.00 & 100.00 & & 1,452 & 100.00 & 100.00 \\
\hline \hline
\end{tabular}

Note: 'Raw Percent' and 'Weighted Percent' indicate whether or not I use the sample weights to correct the sampling bias in the data, respectively. 'Before Truncation' and 'After Truncation' indicate whether or not these samples are truncated by a criterion of having more than 2 shopping trips.

percentage of consumers depending on the number of shopping trips, before and after truncating the data by the number of shopping trips. These four columns suggest that the shape of the histogram would not change dramatically, even though we use the unweighted samples. Moreover, not surprisingly, each individual makes 4.03 shopping trips over the three days on average, implying that there is more than one shopping trip per day, and about half of them have at least four shopping trips. ${ }^{9}$ The fact that we have multiple transactions per person immediately raises a question: Are there any individual-specific patterns in payment choices?

We show consumers' tendency toward payment choice in Table 2. To construct this table, first we categorize the samples into four types by their method of payment choice patterns, regardless of the number of shopping trips. Four types can be found in the first column: (1) Cash users, who use only cash, displayed in the first row, (2) Debit users, who mainly use debit cards, and cash in some cases, displayed in the second and third rows, (3) Credit users who mostly use credit cards, and cash in some cases,

\footnotetext{
${ }^{9}$ This is after dropping observations that are missing perceived acceptance. If we calculate the average shopping trips in the original data, we find that this number should be about 4.7 times per person over the three days.
} 
TABle 2: Patterns of Payment Choice

\begin{tabular}{lrrrr}
\hline \hline & \multicolumn{4}{c}{ Samples with more than } \\
& $\begin{array}{r}\text { \#of } \\
\text { obs. }\end{array}$ & $\begin{array}{r}\text { Weighted } \\
\text { Type of Consumers }\end{array}$ & $\begin{array}{r}\text { avg \# of } \\
\text { shopping }\end{array}$ & $\begin{array}{r}\text { avg } \\
\text { TV }\end{array}$ \\
\hline (1) Cash Users & $\mathbf{2 4 4}$ & 21.81 & 4.45 & 16.58 \\
(2) Debit Users & & & & \\
Only Debit & $\mathbf{6 5}$ & 4.47 & 4.43 & 39.65 \\
Cash \& Debit & $\mathbf{4 5 5}$ & 31.26 & 5.45 & 26.53 \\
(3) Credit Users & & & & \\
Only Credit & $\mathbf{6 0}$ & 3.24 & 4.40 & 43.84 \\
Cash \& Credit & $\mathbf{3 6 0}$ & 22.82 & 5.52 & 29.26 \\
(4) Mixed Users & & & & \\
Debit \& Credit & $\mathbf{4 9}$ & 2.96 & 4.18 & 39.73 \\
All three & $\mathbf{2 1 9}$ & 13.44 & 7.30 & 33.54 \\
\hline Total \# of individuals & $\mathbf{1 , 4 5 2}$ & & 5.45 & \\
Total \# of transactions & $\mathbf{7 , 9 0 8}$ & & & 28.66 \\
\hline \hline
\end{tabular}

Note: Each row shows the types of consumers, and each column shows the number of observations, the average numbers of shopping opportunities, and average transaction values.

displayed in the fourth and fifth rows, and (4) Mixed users who use credit and debit cards, and cash, displayed in the sixth and seventh rows. Then, we count the number of individuals who fall into each category and calculate the number of shopping trips and average transaction values, depending on their types. There are three important observations in this table.

The first and most important observation is the fact that the fractions of debit users and credit users are sizeable, accounting for one-third and one-fourth, respectively. This observation suggests that the substitution between credit and debit cards is very small for those committed users. Small changes in transaction values or in the characteristics of transactions are not necessarily enough for them to switch their payment methods from debit to credit or credit to debit. Thus, the model should take into account the individual-specific effects for their preferred payment methods.

Second, there are some mixed users who use all three methods quite randomly. Although the average number of shopping trips is larger than the corresponding number for other types, the average transaction values for them are not so different from the 
Figure 2: Transaction Value Distributions

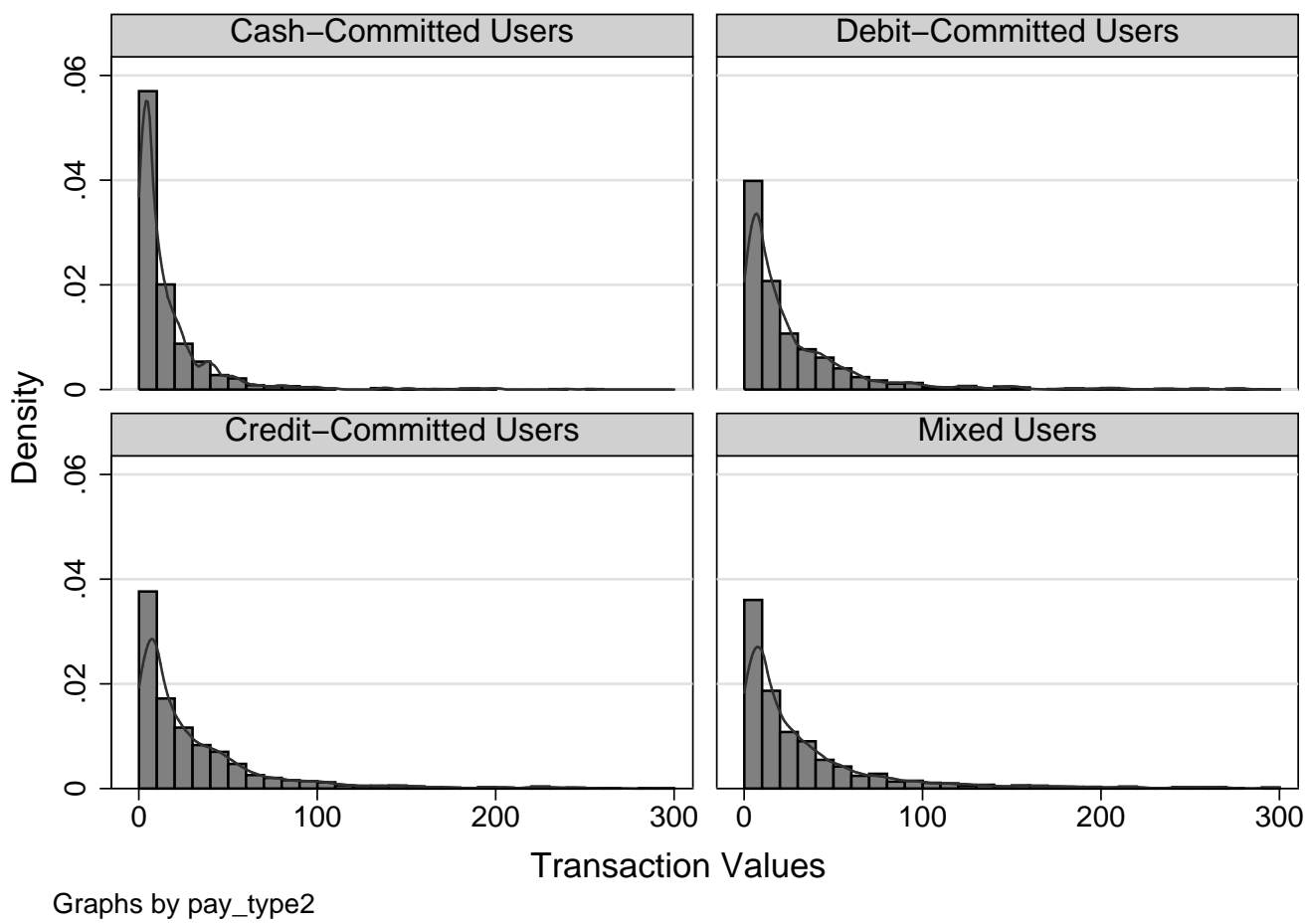

Note: As indicated in each graph, top-left, top-right, bottom-left, and bottom-right panes show the transaction value distributions for each consumer type.

corresponding numbers for credit users. Moreover, as Figure 2 suggests, the distribution of transaction values is quite similar to each other, though their payment choices are quite different. Moreover, we also show each consumer type's payment choice by transaction values in Figure 3. Thus, their preferences should be different from credit users preferences, which should be captured by the model.

As a final remark about Table 2, the distribution of consumer types will be preserved if we limit the samples to consumers with more than 1 shopping opportunity. In order to extract individual-specific effects, e.g., fixed effect estimators and/or random effect estimators, each sample should have multiple observations for identification purposes. Thus, to model the heterogeneity mentioned above, we need to discard the samples which do not have enough observations. To see not only the average but also the distribution of transaction values, we also show the distribution of transaction values depending on the type of consumer, demonstrated in Figure 2. The average transaction 
Figure 3: Methods of Payment by Consumer Type
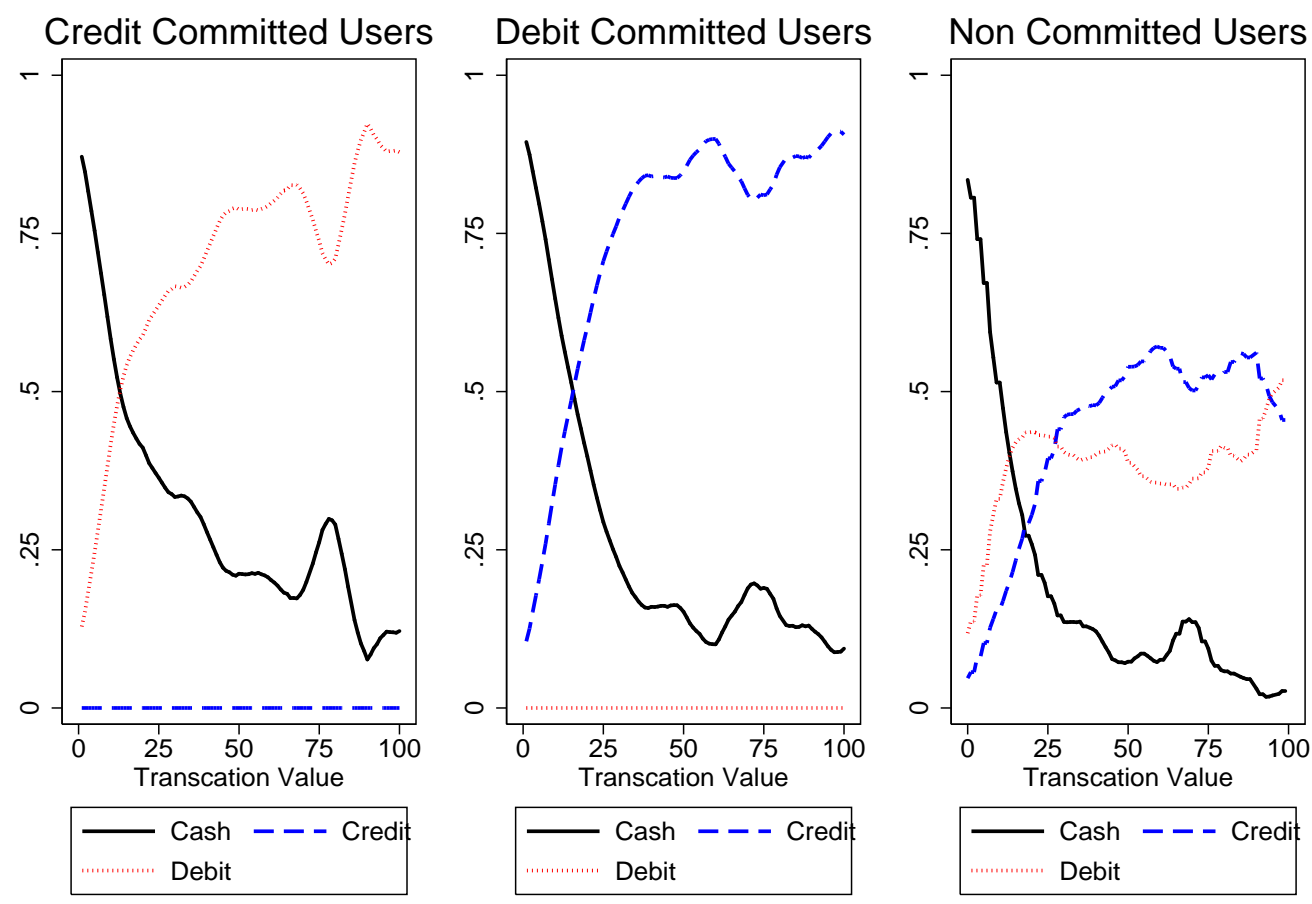

Note: The left, center, and right panel show the frequency of payment choices by transaction value, for credit, debit, and mixed users, respectively.

values and the distribution of the transaction values for each type of consumer are quite similar to each other, implying that consumers with more than three shopping trips are still representative for each type of consumer. Therefore, we estimate the model using the samples with more than two shopping opportunities. ${ }^{10}$

\subsection{Perceived Acceptance}

In addition to the consumer's side, we also describe supply-side information, "perceived acceptance," which is reported by consumers. Although it might have some measurement errors, it is still useful in separating consumers' preference in choosing the method of payment from supply-side factors. Table 3 shows the acceptance of debit and credit cards depending on consumer type. For example, cash users had 1,086 shopping trips in total, and they faced 283 situations where neither debit cards nor credit cards were

\footnotetext{
${ }^{10}$ In order to check the robustness of the results, we also estimate the model using samples with more than six shopping trips.
} 
accepted. Similarly, they could use only cash and debit cards 255 times, and they could use only cash and credit cards 53 times; for the remaining 495 shopping trips, they could use all three methods.

According to Table 3, we can see that the distributions of acceptance are different from each other depending on the type of consumer. For example, debit users are more likely to go to shops that accept debit cards than are credit users, and credit users are more likely to go to shops that accept credit cards than are debit users. However, the differences are quite small between credit users and mixed users. On the other hand, the distributions for cash users and debit users are slightly different from those for other types of people, i.e., they are more likely to go to shops that accept debit or credit cards than are other types of consumers. This difference suggests that there is a potential endogeneity problem, that is, people who prefer using cards might choose shops where these cards are more likely to be accepted. However, the relative number of cash users is small compared to other types, and the patterns of distribution of acceptance are similar to those for other types, i.e., the highest frequency occurs when both credit and debit cards are accepted, and the second highest frequency occurs at shops where neither is accepted, except for debit users. Therefore, this study treats all samples equally in the estimation and we further discuss the potential endogeneity problems in Section 4, together with other issues. 


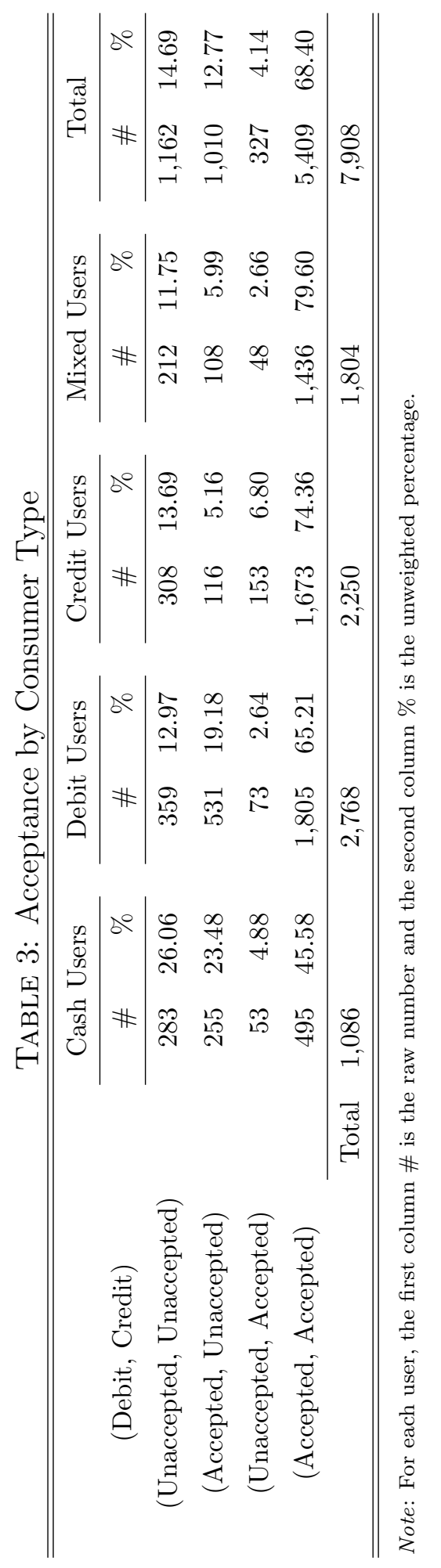


Figure 4: Ease of Use

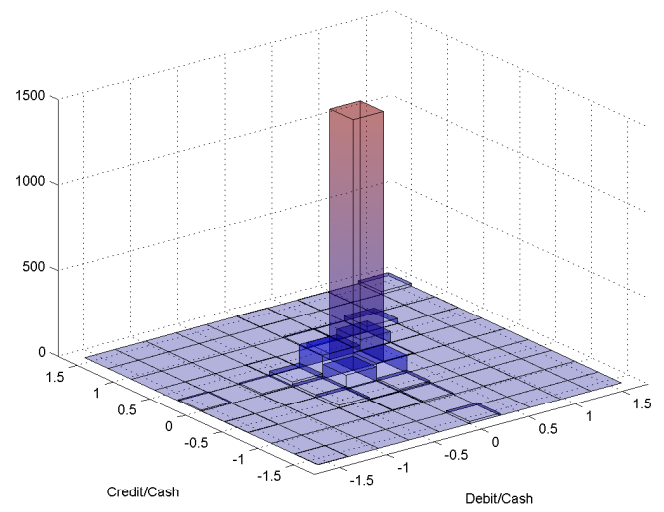

Figure 5: Record Keeping

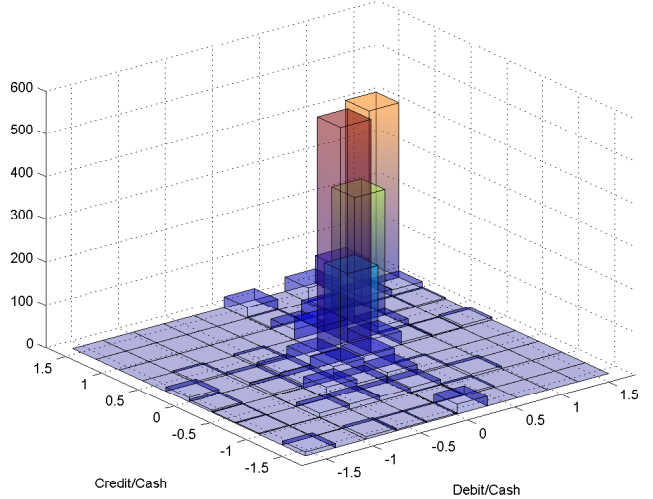

Note: The left graph shows the 3-dimensional histogram of ease-of-use for credit and debit cards relative to cash. Similarly, the right graph shows the 3-dimensional histogram of consumers perception of record keeping facility for credit and debit cards relative to cash.

\subsection{Attitudinal and Other Demographic Variables}

In the questionnaire, respondents were asked to rate the usage of cash, credit cards, and debit cards for (1) the ease of use, and (2) record keeping capabilities, using a five-point scale, e.g., a respondent needs to choose a number from 1 (strongly disagree) to 5 (strongly agree) to rate the ease of use for each method of payment. We normalize those two ratings by cash. That is, each index for credit card and debit card usage is obtained by

$$
a_{i, j, l}=\log \left(\frac{r_{i, j, l}}{r_{i, c a s h, l}}\right)
$$

where $r_{i, j, l}$ is the rating of individual $i$ for payment method $j, j=$ credit and debit, and $l$ denotes the ease of use or record keeping. Taking logarithm normalizes the indexes so that $a_{i, j, l}$ can take a value between -1.6094 to 1.6094 , and 0 if payment method $j$ is identical to cash.

Figures 4 and 5 graphically show the respondents' attitudinal and perceptual data, using 3-dimensional histograms. For example, Figure 4 shows that many respondents are located at the center, at the point of $(0,0)$, implying most of them think the ease of use for all three methods are the same. On the other hand, Figure 5 shows that many respondents are located north of $(0,0)$, implying that credit and debit cards are more convenient as a record keeping device than cash. 


\section{Econometric Model}

This section provides a payment choice model for consumers. As indicated in Section 2, consumers' payment choice is a discrete outcome variable. Thus, given the discrete nature of the data and motivated by some patterns observed in Section 2, this paper uses a generalized multinomial logit model, as proposed by Fiebig, Keane, Louviere, and Wasi (2010). ${ }^{11}$ As a benchmark case, we also estimate a series of multinomial logit models to compare the estimation results and statistical fitness of the model.

\subsection{Payment Choice Model}

Suppose the utility function for individual $i, i=1,2, \cdots, N$, at shopping trip $t, t=$ $1,2, \cdots, T_{i}$, from choosing payment method $j \in \mathscr{J}_{i t}$ is given by:

$$
u_{i j t}=\alpha_{j}+\boldsymbol{Z}_{i t} \boldsymbol{\beta}_{i}^{Z}+\boldsymbol{A}_{i j} \boldsymbol{\beta}_{i}^{A}+\boldsymbol{D}_{i} \boldsymbol{\beta}_{i}^{D}+\varepsilon_{i j t},
$$

where $\alpha_{j}$ is a payment method specific constant term, $\boldsymbol{Z}_{i t}$ is an $M_{Z}$-dimensional vector of shopping characteristics, $\boldsymbol{A}_{i j}$ is an $M_{A}$-dimensional vector of individual $i$ 's attitudinal characteristics toward the payment method $j, \boldsymbol{D}_{i}$ is an $M_{D^{-}}$dimensional vector of individual $i$ 's demographic information, $\boldsymbol{\beta}_{i}=\left[\begin{array}{l}\boldsymbol{\beta}_{i}^{Z} \\ \boldsymbol{\beta}_{i}^{A}\end{array} \boldsymbol{\beta}_{i}^{D}\right]$ is a coefficient vector, and $\varepsilon_{i j t}$ is an i.i.d. random utility shock that follows a Type I extreme value distribution. ${ }^{12}$ Each individual $i$ chooses a payment method $j$ which gives the highest utility at shopping trip $t$. As a matter of convention, the utility from using cash is normalized as zero,

\footnotetext{
${ }^{11}$ There exist other approaches: semiparametric and nonparametric approaches. For example, after the pioneering work of Manski (1975), Briesch, Chintagunta, and Matzkin (2002) use a semi-parametric method, known as maximum score estimator, to extract unobserved heterogeneity in discrete choice models. More recently, Fox (2007) shows that the semiparametric estimator is consistent when using data on a subset of choices. Similarly, Briesch, Chintaguanta, and Matzkin (2010) use nonparametric approach to extract unobserved heterogeneity in discrete choice models.

${ }^{12}$ As Fiebig, Keane, Louviere, and Wasi (2010) point out, a choice specific constant term, $\alpha_{j}$, cannot be individual-specific, i.e., we cannot identify when $\alpha_{j}$ is replaced by $\alpha_{i j}$. This problem is known as "incidental parameter problem," studied by Neyman and Scott (1948) and thus we explicitly write $\alpha_{j}$ separately from other characteristics. For more details, see Lancaster (2000) which is a comprehensive survey of this issue. Moreover, a recent study by Fox, il Kim, Ryan, and Bajari (2012) shows that the distribution of the random coefficients in the multinomial logit model is nonparametrically identified, and we can straightforwardly apply their identification argument to this model.
} 
i.e., we assume that $u_{i, c a s h, t}=0$. For notational simplicity, we use $\boldsymbol{X}_{i j t}=\left[\begin{array}{ll}\boldsymbol{Z}_{i t} & \boldsymbol{A}_{i j} \\ \boldsymbol{D}_{i}\end{array}\right]$, which gives us a standard notation of the utility:

$$
u_{i j t}=\alpha_{j}+\boldsymbol{X}_{i j t} \boldsymbol{\beta}_{i}^{\prime}+\varepsilon_{i j t}
$$

Though $\boldsymbol{\beta}_{i}$ may depend on a payment method $j$, we suppress the subscript for transparency. Here, we specify an $m$-th element of $\boldsymbol{\beta}_{i}$ as

$$
\begin{aligned}
\beta_{i m} & =\sigma_{i} \bar{\beta}_{m}+\gamma \eta_{i m}+(1-\gamma) \sigma_{i} \eta_{i m}, \quad \text { where } \eta_{i m} \sim N\left(0, \beta_{m}^{u}\right) \\
\sigma_{i} & =\exp \left(\bar{\sigma}+\tau \epsilon_{i 0}\right), \quad \text { where } \epsilon_{i 0} \sim N(0,1),
\end{aligned}
$$

where $\eta_{i m}$ is individual-specific deviation from the mean, which follows a standard normal or log-normal distribution, $\sigma_{i}$ is a scale heterogeneity, which follows a log-normal distribution, and $\gamma$ is a mixing parameter that decides the degree of two heterogeneous effects. ${ }^{13}$ As for a scaling heterogeneity $\sigma_{i}$, we use an exponential operator to avoid negative scaling and $\tau$ can be seen as a scaling parameter, because it essentially changes the absolute scale of $\sigma_{i}$. we explain the roles of these two heterogeneity parameters below.

In the standard (multinomial) logit model, $\beta_{i m}=\bar{\beta}_{m}$, which implies that all individuals have exactly the same taste for all characteristics. As repeatedly emphasized in this paper, however, the data show heterogeneity in payment choice. Thus, as in equation (2), the model includes two heterogeneity parameters: $\sigma_{i}$ and $\boldsymbol{\eta}_{i}$, where $\boldsymbol{\eta}_{i}=\left[\eta_{i 1}, \cdots, \eta_{i M}\right]$. To see the importance of $\boldsymbol{\eta}_{i}$, assume that $\sigma_{i}=1$ and $\gamma=1$. Then, equation (2) can be simplified as

$$
\begin{aligned}
\text { Mixed (Heterogeneous) Logit: } & \beta_{i m}=\bar{\beta}_{m}+\eta_{i m}, \text { where } \eta_{i m} \sim N\left(0, \beta_{m}^{u}\right), \\
\text { cf. A Standard Logit: } & \beta_{i m}=\bar{\beta}_{m} .
\end{aligned}
$$

Now, it is clear that the $\bar{\beta}_{m}$ is a mean valuation for $m$-th characteristics and the $\eta_{i m}$ is an individual specific taste deviation from the mean in payment choice. For example, suppose each shopping trip is characterised by its transaction value and consumers only care about the transaction value (TV) when they make a decision. Some consumers

\footnotetext{
${ }^{13}$ As Fiebig, Keane, Louviere, and Wasi (2010) mention, there is no good economic interpretation for $\gamma$.
} 
who use credit cards regardless of the transaction values and rarely use cash have higher values of $\eta_{i, T V}$, whereas consumers who only use cash have smaller (or negative) values of $\eta_{i, T V}$. Therefore, this term enables individuals to have heterogeneous tastes by changing the thresholds of each payment method. This model is called mixed logit, heterogeneous logit, or random coefficients model. ${ }^{14}$

The other heterogeneity parameter, $\sigma_{i}$, is a scale heterogeneity. To emphasize the importance of $\sigma_{i}$, again, assume $\gamma=0$. Then, equation (2) can be rewritten as

$$
\beta_{i m}=\sigma_{i}\left(\bar{\beta}_{m}+\eta_{i m}\right), \quad \text { where } \eta_{i m} \sim N\left(0, \beta_{m}^{u}\right) .
$$

As the name suggests, the scale heterogeneity is indeed scaled up or down the valuation for the particular choice, which is constant across $m$, and can capture the committed users' behavior well.

Notice that this class of model includes a lot of models as special cases, as indicated above. For example, assuming $\sigma_{i}=1$ and $\beta_{m}^{u}=0$ for all $m$, this model boils down to the simplest (multinomial) logit model. Also, as mentioned above, assuming $\sigma_{i}=1$, this model will be identical to the models in Revelt and Train (1998) and Train (1998), i.e., $\beta_{i m}$ can be simplified as $\beta_{i m}=\bar{\beta}_{m}+\eta_{i m}$, which is the standard mixed logit or heterogeneous logit model. In this study, we assume that $\gamma=0$, which gives us $\beta_{i m}=\sigma_{i}\left(\bar{\beta}_{m}+\eta_{i m}\right)$ and we call $\sigma_{i}$ a scale heterogeneity and $\eta_{i m}$ random coefficients. Moreover, we also assume that the variance-covariance matrix of $\boldsymbol{\eta}_{i}$ is diagonal to ease computational complexity.

A scale coefficient might be explained by the individual demographic information. For example, credit card users are likely to have high income. Thus, the scale heterogeneity for credit cards might be explained by users' income. Generally speaking, if we want to explain $\sigma$ with some demographic information, it can be written as

$$
\sigma_{i}=\exp \left(\bar{\sigma}+\boldsymbol{Q}_{i} \boldsymbol{\beta}^{q}+\tau \epsilon_{i 0}\right)
$$

where $\boldsymbol{Q}_{i}$ denotes the individual demographics, such as income or age, which might explain the scale heterogeneity, and $\boldsymbol{\beta}^{q}$ is a coefficient vector. This seemingly slight

\footnotetext{
${ }^{14}$ This model can be seen as one of the random effects models. The reason we use a random effects model here is the fact that we can only have several observations for most of the samples. In order to deal with this heterogeneity as fixed effects, we need to have more observations per each individual.
} 
change requires huge computational complexity, because we need to find $\bar{\sigma}$ that satisfies

$$
\int_{\epsilon_{i 0}} \exp \left(\bar{\sigma}+\boldsymbol{Q}_{i} \boldsymbol{\beta}^{q}+\tau \epsilon_{i 0}\right) d F\left(\epsilon_{i 0}\right)=1
$$

as a normalization. ${ }^{15}$ Thus, first we need to find $\bar{\sigma}$ as a function of the parameter values of $\boldsymbol{\theta}$, including $\tau$, and then we plug $\bar{\sigma}$ into the equation to simulate the choice probabilities.

The choice set for consumer $i$ at shopping opportunity $t$ is defined by $\mathscr{J}_{i t}$. Fortunately, we can observe this information in the data. Although it might have measurement errors, we can observe the consumers' "perceived" acceptance at the time of transaction and we use that information to limit the choice set for consumers. Moreover, we can observe whether consumer $i$ owns any credit or debit cards. Thus, if individual $i$ does not have credit and/or debit cards, we exclude credit or debit cards from individual $i$ 's choice set.

\subsection{A Maximum Simulated Likelihood Estimator}

Given the parameter values $\boldsymbol{\theta}=\left\{\left\{\alpha_{j},\left\{\bar{\beta}_{m j}, \beta_{m j}^{u}\right\}_{m=1, \cdots, M_{j}}, \tau_{j}\right\}_{j=C C, D C}\right\}$, where CC and DC denote the credit card and debit card, and a pair of random draws of $\left(\boldsymbol{\epsilon}_{i}, \boldsymbol{\eta}_{i}\right)$ that are fixed over the estimation procedure, we can obtain the analytical choice probability of individual $i$ choosing payment method $j$ at shopping trip $t$ as

$$
\mathrm{P}\left(y_{i j t}=1 \mid \boldsymbol{X}_{i j t}, \boldsymbol{\theta}, \boldsymbol{\epsilon}_{i}, \boldsymbol{\eta}_{i}\right)=\frac{\exp \left(\alpha_{j}+\boldsymbol{X}_{i j t}^{\prime} \boldsymbol{\beta}_{i}\right)}{\sum_{l \in \mathscr{I}_{i t}} \exp \left(\alpha_{l}+\boldsymbol{X}_{i l t}^{\prime} \boldsymbol{\beta}_{i}\right)},
$$

where

$$
y_{i j t}= \begin{cases}1, & \text { if } i \text { choose option } j \text { at shopping trip } t \\ 0, & \text { otherwise. }\end{cases}
$$

Notice that the denominator in equation (5) is a summation over available choices. For example, if a choice set only includes cash and debit card, the denominator is a summation of exponentiated utility from cash usage and debit card usage. Using this

\footnotetext{
${ }^{15}$ In order to identify multiplicative heterogeneity, one of the heterogeneity parameters should be normalized. See Fiebig, Keane, Louviere, and Wasi (2010).
} 
choice probability, the likelihood contribution for each individual is given by:

$$
\mathscr{L}_{i}(\boldsymbol{\theta})=\int_{\left(\epsilon_{i}, \eta_{i}\right)} \prod_{t=1}^{T_{i}} \prod_{j}\left[\mathrm{P}\left(y_{i j t}=1 \mid \boldsymbol{X}_{i j t}, \boldsymbol{\theta}, \boldsymbol{\epsilon}_{i}, \boldsymbol{\eta}_{i}\right)\right]^{d_{i j t}} d F\left(\boldsymbol{\epsilon}_{i}, \boldsymbol{\eta}_{i}\right),
$$

where $d_{i j t}$ is the observed decision defined by

$$
d_{i j t}= \begin{cases}1, & \text { if } i \text { choose option } j \text { at a shopping trip } t \\ 0, & \text { otherwise. }\end{cases}
$$

As in equation (6), the individual likelihood contribution is a product over the shopping trips for $T_{i}$ times. In other words, we stack multiple transactions at the individual level. In this way, we can capture the individual heterogeneity. If we do not stack multiple transactions at the individual level, the model is unable to capture individual heterogeneity and is identical to assuming that each transaction is independent and identically distributed.

Unfortunately, we cannot directly calculate this likelihood function, and thus we use the simulation technique to approximate it. Namely, suppose a random draw is indexed by $s$, i.e., we have $\left\{\boldsymbol{\epsilon}_{i}^{s}, \boldsymbol{\eta}_{i}^{s}\right\}_{s=1, \cdots, S}$ for each individual. Then, the likelihood contribution for each individual should be approximated by

$$
\mathscr{L}_{i}(\boldsymbol{\theta}) \approx \frac{1}{S} \sum_{s=1}^{S} \prod_{t=1}^{T_{i}} \prod_{j}\left[\mathrm{P}\left(y_{i j t}=1 \mid \boldsymbol{X}_{i j t}, \boldsymbol{\theta}, \boldsymbol{\epsilon}_{i}^{s}, \boldsymbol{\eta}_{i}^{s}\right)\right]^{d_{i j t}}
$$

which enables us to define the simulated maximum likelihood (SML) estimator given by:

$$
\hat{\boldsymbol{\theta}}^{\mathrm{SML}}=\arg \max _{\boldsymbol{\theta}} \sum_{i=1}^{N} w_{i} \log \left(\mathscr{L}_{i}(\boldsymbol{\theta})\right)
$$

Notice that the log likelihood value is weighted by $w_{i}$ to correct the sampling bias, as discussed in Section 2. The standard errors reported in this study are calculated by

$$
\operatorname{Avar}\left(\hat{\boldsymbol{\theta}}^{\mathrm{SML}}\right)=\sum_{i=1}^{N} w_{i} \boldsymbol{s}_{i}\left(\hat{\boldsymbol{\theta}}^{\mathrm{SML}}\right)^{\prime} \boldsymbol{s}_{i}\left(\hat{\boldsymbol{\theta}}^{\mathrm{SML}}\right)
$$

where $\boldsymbol{s}\left(\hat{\boldsymbol{\theta}}^{\mathrm{SML}}\right)$ is a score vector evaluated at $\hat{\boldsymbol{\theta}}^{\mathrm{SML}}$. Notice, again, that we need to take into account the sample weight to adjust the sampling bias. Under regularity 
conditions, this estimator is consistent and asymptotically normal.

\section{Results}

\subsection{Estimation Results}

This section provides the estimation results, focusing on the differences among alternative modellings. To emphasize the importance of each heterogeneity, we estimate six variations of the model, summarized in Table 4. In order to address the importance of the "perceived acceptance," we estimate the model with and without limiting consumers' choice sets based on their reported perceived acceptance. Furthermore, to understand the difference between transaction-level and individual-level data, we estimate the model at transactional level, assuming each transaction is i.i.d, and individual level storing the multiple transactions per subject. Finally, to see the importance of variations of individual heterogeneity, we estimate four models with and without including $\boldsymbol{\epsilon}$ and $\boldsymbol{\mu}$. As for simulation, we use 500 sets of random draws per subject, i.e., $\left\{\boldsymbol{\epsilon}_{i}^{s}, \boldsymbol{\eta}_{i}^{s}\right\}_{i=1, \cdots, N ; s=1, \cdots, 500 \cdot{ }^{16}}$

TABLE 4: Variations of Estimated Models

\begin{tabular}{lcccccc}
\hline \hline & \multicolumn{7}{c}{ Model } \\
\cline { 2 - 7 } & (i) & (ii) & (iii) & (iv) & (v) & (vi) \\
\hline (1) Transaction/Individual & Trans. & Trans. & Ind. & Ind. & Ind. & Ind. \\
(2) Choice Sets & Unlimited & Limited & Limited & Limited & Limited & Limited \\
(3) Scale Hetero. $(\sigma)$ & No & No & No & Yes & No & Yes \\
(4) Random Coeff. $(\mu)$ & No & No & No & No & Yes & Yes \\
\hline \hline
\end{tabular}

Note: In the first row, 'Trans.' means that I use transactional-level data, assuming each transaction is independent and identically distributed and 'Ind.' means that I stack multiple observations for each individual to extract individual heterogeneity. In the second row, 'limited' and 'Unlimited' stand for limiting and not limiting choice sets by perceived acceptance data reported by respondents.

Parameter Values and Statistics Tables 5 and 6 show the estimation results and some summary statistics. As mentioned in Section 3, we normalize the utility of using

16 Revelt and Train (1998) use the same number of simulations for their estimation procedure. Notice that the estimator is consistent and asymptotically normal under regularity conditions. 
cash to zero. Thus, we show the coefficients for credit and debit cards, listing the included variables in the first column of each table. Each coefficient is interpreted as follows: Transaction value (abbreviated as TV in the first column) and its squared term for credit cards is positive and negative, respectively, implying that the utility of using credit cards is increasing in transaction values with marginally decreasing. Those people who valuate the ease of use and record keeping facility of credit cards are likely to use credit cards, since the utility of using credit cards is higher. Estimation results also suggest that if people have multiple credit cards, a higher credit limit, or higher reward points for their primary credit cards, their latent utility of using credit cards is high. On the other hand, when people face very low transaction values or are young, they are less likely to use credit cards.

As for debit card usage, consumers are more likely to use debit cards, if the transaction value is very low, or if consumers are young and have less income. On the other hand, as transaction values increase, or if the transactions took place at a grocery store, and consumers have multiple debit cards or evaluate debit cards' ease of use and record keeping facility, then they are more likely to use debit cards. Although the magnitude of significance might change across the models, these coefficients basically show the same sign and statistical significance.

In terms of the summary statistics, the values of log likelihood, AIC and BIC improve by limiting the choice sets, shifting from Model (i) to Model (ii). Notice that the estimation results for Models (ii) and (iii) are the same, as the objective functions are identical when the models do not have any random coefficients. Although the estimates are the same, the standard errors should be different as indicated in Table 5. Thus, without taking into account the unobserved individual-specific effects, the usage of transaction-level and individual-level data should yield the same estimates. ${ }^{17}$

When we introduce the heterogeneity terms in Models (iv) to (vi), the log likelihood, AIC and BIC further improve dramatically as indicated in Table $6 .{ }^{18}$ In Model (iv), we introduce a scale coefficient and it is indeed statistically significant. Moreover, in Model (v), we use the random coefficients for transaction values, ease of use, and so

\footnotetext{
${ }^{17}$ You can also see these results analytically.

${ }^{18}$ When adding more parameters in a statistical model, the statistical goodness of fit, say likelihood value, may improve. Thus, the Akaike information criterion and the Bayesian information criterion solve this problem by having a penalty term for the number of parameters.
} 
TABle 5: Estimation Results 1/2

\begin{tabular}{|c|c|c|c|c|c|c|}
\hline & \multicolumn{2}{|c|}{ Model (i) } & \multicolumn{2}{|c|}{ Model (ii) } & \multicolumn{2}{|c|}{ Model (iii) } \\
\hline & Est. & S.E. & Est. & S.E. & Est. & S.E. \\
\hline \multicolumn{7}{|l|}{ Credit Cards } \\
\hline Constant & -3.0099 & 0.2491 & -2.4129 & 0.2582 & -2.4129 & 0.1638 \\
\hline $\mathrm{TV}$ & 1.1451 & 0.0936 & 1.1125 & 0.1189 & 1.1125 & 0.0783 \\
\hline TV sq & -0.2733 & 0.0318 & -0.2337 & 0.0517 & -0.2337 & 0.0394 \\
\hline Less than $\$ 5$ & -1.5953 & 0.2067 & -1.4850 & 0.2128 & -1.4850 & 0.2200 \\
\hline Less than $\$ 10$ & -0.9901 & 0.1393 & -0.8560 & 0.1500 & -0.8560 & 0.1372 \\
\hline Grocery Store & -0.01646 & 0.1054 & -0.4068 & 0.1112 & -0.4068 & 0.0881 \\
\hline Entertainment & -0.4971 & 0.1123 & -0.6468 & 0.1237 & -0.6468 & 0.1131 \\
\hline Age & -1.5787 & 0.1561 & -1.2256 & 0.1676 & -1.2256 & 0.1145 \\
\hline Income & 0.1654 & 0.1023 & 0.2192 & 0.1096 & 0.21917 & 0.0727 \\
\hline Ease of Use & 0.0882 & 0.0155 & 0.1039 & 0.0172 & 0.1039 & 0.0103 \\
\hline Record Keeping & 0.4444 & 0.0543 & 0.4968 & 0.0590 & 0.4968 & 0.0381 \\
\hline Num. of CC & 0.1780 & 0.0571 & 0.1493 & 0.0616 & 0.1493 & 0.0405 \\
\hline Credit Reward & 0.1102 & 0.0289 & 0.1654 & 0.0287 & 0.1654 & 0.0174 \\
\hline Credit Limit & 2.0117 & 0.1473 & 1.5700 & 0.1505 & 1.5700 & 0.1010 \\
\hline $\mathrm{RC}$ for $\mathrm{TV}$ & - & - & - & - & - & - \\
\hline $\mathrm{RC}$ for Ease & - & - & - & - & - & - \\
\hline $\mathrm{RC}$ for Record & - & - & - & - & - & - \\
\hline RC for Num. CC & - & - & - & - & - & - \\
\hline $\mathrm{RC}$ for Rewards & - & - & - & - & - & - \\
\hline RC for C Limit & - & - & - & - & - & - \\
\hline Scale Coeff. & - & - & - & - & - & - \\
\hline \multicolumn{7}{|l|}{ Debit Cards } \\
\hline Constant & -0.1693 & 0.1943 & 0.2316 & 0.2056 & 0.2316 & 0.1393 \\
\hline $\mathrm{TV}$ & 0.8697 & 0.0864 & 0.8684 & 0.1087 & 0.8684 & 0.0558 \\
\hline $\mathrm{TV}$ sq & -0.2320 & 0.0315 & -0.2070 & 0.0489 & -0.2070 & 0.0329 \\
\hline Less than $\$ 5$ & -1.1890 & 0.1380 & -1.0181 & 0.1424 & -1.0181 & 0.1389 \\
\hline Less than $\$ 10$ & -0.8779 & 0.1118 & -0.8427 & 0.1190 & -0.8427 & 0.1097 \\
\hline Grocery Store & 0.7652 & 0.0870 & 0.3927 & 0.0910 & 0.3927 & 0.0790 \\
\hline Entertainment & -0.1574 & 0.0995 & -0.3056 & 0.1060 & -0.3056 & 0.0886 \\
\hline Age & -1.3127 & 0.1260 & -1.1877 & 0.1319 & -1.1877 & 0.0906 \\
\hline Income & -0.3166 & 0.0767 & -0.3562 & 0.0818 & -0.3562 & 0.0552 \\
\hline Ease of Use & 0.0999 & 0.0158 & 0.1094 & 0.0172 & 0.1094 & 0.0116 \\
\hline Record Keeping & 0.1548 & 0.0449 & 0.2293 & 0.0483 & 0.2293 & 0.0310 \\
\hline Num. of DC & 0.4817 & 0.0646 & 0.4212 & 0.0682 & 0.4211 & 0.0445 \\
\hline $\mathrm{RC}$ for $\mathrm{TV}$ & - & - & - & - & - & - \\
\hline $\mathrm{RC}$ for Ease & - & - & - & - & - & - \\
\hline $\mathrm{RC}$ for Record & - & - & - & - & - & - \\
\hline RC for Num DCs & - & - & - & - & - & - \\
\hline Scale Coeff. & - & - & - & - & - & - \\
\hline \multicolumn{7}{|l|}{ Summary Statistics } \\
\hline No. of Param. & 26 & & 26 & & 26 & \\
\hline Log Likelihood & -5420.2 & & -4694.7 & & -4694.7 & \\
\hline $\mathrm{AIC}$ & 10892 & & 9441.5 & & 9441.5 & \\
\hline $\mathrm{BIC}$ & 11074 & & 9622.9 & & 9578.8 & \\
\hline
\end{tabular}

Note: The bold numbers in the estimates columns are statistically significant at the $5 \%$ level. 
TABLE 6: Estimation Results 2/2 (Continued)

\begin{tabular}{|c|c|c|c|c|c|c|}
\hline & \multicolumn{2}{|c|}{ Model (iv) } & \multicolumn{2}{|c|}{ Model (v) } & \multicolumn{2}{|c|}{ Model (vi) } \\
\hline & Est. & S.E. & Est. & S.E. & Est. & S.E. \\
\hline \multicolumn{7}{|l|}{ Credit Cards } \\
\hline Constant & -4.6344 & 0.4396 & -3.5565 & 0.4551 & -3.5420 & 0.4901 \\
\hline TV & 1.7639 & 0.1542 & 1.7726 & 0.1558 & 1.6815 & 0.1656 \\
\hline TV sq & -0.3526 & 0.0995 & -0.3177 & 0.0820 & -0.3119 & 0.0749 \\
\hline Less than $\$ 5$ & -1.1668 & 0.8146 & -2.0460 & 0.3124 & -2.0309 & 0.3138 \\
\hline Less than $\$ 10$ & -0.8620 & 0.2731 & -1.4553 & 0.2199 & -1.4935 & 0.2204 \\
\hline Grocery Store & -0.4510 & 0.1528 & -0.7376 & 0.1671 & -0.7305 & 0.1680 \\
\hline Entertainment & -0.9530 & 0.1820 & -1.2977 & 0.1743 & -1.3001 & 0.1784 \\
\hline Age & -0.6100 & 0.2234 & -1.5259 & 0.3996 & -1.4413 & 0.4005 \\
\hline Income & 0.5825 & 0.1433 & 0.6159 & 0.2393 & 0.6415 & 0.2403 \\
\hline Ease of Use & 0.0023 & 0.0310 & 0.1508 & 0.0949 & 0.1743 & 0.0969 \\
\hline Record Keeping & 0.4492 & 0.0766 & 0.7474 & 0.1659 & 0.7970 & 0.1414 \\
\hline Num. of CC & 0.2622 & 0.0788 & 0.3608 & 0.2038 & 0.2809 & 0.1722 \\
\hline Credit Reward & 0.3717 & 0.0413 & 0.4113 & 0.1645 & 0.4135 & 0.1553 \\
\hline Credit Limit & 2.0087 & 0.2180 & 1.2755 & 0.4348 & 1.3860 & 0.4184 \\
\hline $\mathrm{RC}$ for $\mathrm{TV}$ & - & - & -0.4567 & 0.1875 & 0.2108 & 0.2982 \\
\hline $\mathrm{RC}$ for Ease & - & - & -0.3803 & 0.0912 & -0.4017 & 0.0985 \\
\hline $\mathrm{RC}$ for Record & - & - & -0.1079 & 0.5921 & - & - \\
\hline RC for Num. CC & - & - & -0.1824 & 0.6545 & - & - \\
\hline $\mathrm{RC}$ for Rewards & - & - & 0.8540 & 0.2385 & 0.8210 & 0.2201 \\
\hline RC for C Limit & - & - & 1.8205 & 0.2132 & -1.5863 & 0.2161 \\
\hline Scale for CC & -0.5342 & 0.0457 & & & -0.2338 & 0.0956 \\
\hline \multicolumn{7}{|l|}{ Debit Cards } \\
\hline Constant & 3.5675 & 0.1958 & 1.2762 & 0.4338 & 1.8895 & 0.2457 \\
\hline $\mathrm{TV}$ & 0.8172 & 0.1023 & 1.0749 & 0.1065 & 1.3615 & 0.1678 \\
\hline TV sq & -0.1400 & 0.0403 & -0.2242 & 0.0537 & -0.2832 & 0.0648 \\
\hline Less than $\$ 5$ & -3.1921 & 0.4493 & -1.2917 & 0.1846 & -3.4816 & 0.5343 \\
\hline Less than $\$ 10$ & -2.9933 & 0.3666 & -1.3868 & 0.1729 & -2.5528 & 0.3903 \\
\hline Grocery Store & 0.5807 & 0.1432 & 0.5748 & 0.1249 & 0.8743 & 0.1947 \\
\hline Entertainment & -1.1524 & 0.2475 & -0.4254 & 0.1441 & -1.0243 & 0.2734 \\
\hline Age & -3.8548 & 0.2946 & -2.1717 & 0.2712 & -3.5558 & 0.3947 \\
\hline Income & -1.2672 & 0.1929 & -0.8009 & 0.1777 & -1.3882 & 0.2832 \\
\hline Ease of Use & 0.1708 & 0.0194 & 0.1595 & 0.0656 & 0.2283 & 0.0458 \\
\hline Record Keeping & 0.2036 & 0.1156 & 0.2708 & 0.1603 & 0.2956 & 0.2694 \\
\hline Num. of DC & -0.3539 & 0.1721 & 0.2548 & 0.3328 & 0.5346 & 0.3807 \\
\hline $\mathrm{RC}$ for $\mathrm{TV}$ & - & - & 0.4337 & 0.1619 & 0.3723 & 0.2217 \\
\hline $\mathrm{RC}$ for Ease & - & - & -0.1539 & 0.1284 & - & - \\
\hline $\mathrm{RC}$ for Record & - & - & -0.6375 & 0.2422 & -1.7222 & 0.3034 \\
\hline RC for Num DCs & - & - & 2.0838 & 0.1927 & 2.1846 & 0.3294 \\
\hline Scale for DC & -0.6707 & 0.0389 & & & -0.7431 & 0.0570 \\
\hline \multicolumn{7}{|l|}{ Summary Statistics } \\
\hline No. of Param. & 28 & & 36 & & 35 & \\
\hline Log Likelihood & -4071.2 & & -3972.1 & & -3948.6 & \\
\hline $\mathrm{AIC}$ & 8198.5 & & 8016.1 & & 7967.3 & \\
\hline $\mathrm{BIC}$ & 8346.3 & & 8206.2 & & 8152.1 & \\
\hline
\end{tabular}

Note: The bold numbers in the estimates columns are statistically significant at the $5 \%$ level. 
on. In Table 6, 'RC' indicates a random coefficient and the bold numbers indicate statistical significance at the $5 \%$ level. Although some random coefficients are statistically insignificant, more than half of the random coefficients are statistically significant, implying that consumers' valuations for payment characteristics are quite heterogeneous. Furthermore, we introduce both random and scale coefficients in Model (vi). Again, most of the parameters are statistically significant.

As for the statistical fitness of the model, we present AIC and BIC at the bottom of Tables 5 and 6. Models (i) to (iii) force everybody to have homogeneous taste parameters, and these models show relatively larger AIC and BIC than Models (iv) to (vi). Thus, the statistical fitness of the model and the statistical significance of some random coefficient terms indicate the importance of individual heterogeneity. Model (vi) achieves the smallest log-likelihood, AIC, and BIC. These statistics for the fitness of the models are enough for us to proceed to the counterfactual simulations, we also show some predicted probabilities using the estimated models to show other aspects of the fitness of the models.

Predicted Probabilities Table 7 demonstrates the overall fitness of the estimated models. Each column shows the shares of cash, credit and debit cards in terms of the frequency (volume) share in the top three rows and value share in the bottom three rows. Since the objective function of the models is based on the individual loglikelihood contribution, we use the weight multiplied by the number of transactions per person. That is, we use $w^{P}=w_{i} T_{i}$, where $T_{i}$ is the total number of shopping trips that individual $i$ had, and the estimated parameters to calculate the predicted shares. ${ }^{19}$

Model (iii) or (vi) can be seen as one of the most promising models in Table 7 , as both models mimic the data quite well in both frequency and values share. At the same time, other models also mimic each share within almost $\pm 1 \%$ range. Moreover, even for value shares that we do not match directly in the estimation procedure, these four models mimic the data well. However, Table 8 suggests that Model (iii)

\footnotetext{
${ }^{19}$ Each predicted share can be obtained via:

$$
s_{j}^{F}=\sum_{i=1}^{N} \sum_{t=1}^{T_{i}}\left[\frac{1}{R} \sum_{r=1}^{R} w^{P} \mathrm{P}\left(y_{i j t}=1 \mid \boldsymbol{X}_{i j t}, \boldsymbol{\theta}, \sigma_{i}^{r}, \eta_{i}^{r}\right)\right]
$$
}

where $R=1,000$ and each choice probability is given by Equation (5). 
TABle 7: Model Fit - Overall Fitness

\begin{tabular}{lccccc}
\hline \hline & & \multicolumn{4}{c}{ Model Prediction } \\
\cline { 3 - 6 } & Data & Model (iii) & Model (iv) & Model (v) & Model (vi) \\
\hline Frequency Share & & & & & \\
$\quad$ Cash & $57.20 \%$ & $56.21 \%$ & $56.72 \%$ & $56.55 \%$ & $56.48 \%$ \\
$\quad$ Credit & $18.61 \%$ & $18.61 \%$ & $19.01 \%$ & $19.37 \%$ & $19.17 \%$ \\
$\quad$ Debit & $24.19 \%$ & $25.18 \%$ & $24.27 \%$ & $24.07 \%$ & $24.35 \%$ \\
Value Share & & & & & \\
$\quad$ Cash & $30.48 \%$ & $30.27 \%$ & $32.24 \%$ & $31.56 \%$ & $31.27 \%$ \\
$\quad$ Credit & $34.83 \%$ & $34.51 \%$ & $34.85 \%$ & $35.25 \%$ & $35.00 \%$ \\
$\quad$ Debit & $34.69 \%$ & $35.22 \%$ & $32.92 \%$ & $33.19 \%$ & $33.73 \%$ \\
\hline \hline
\end{tabular}

Note: As indicated in Table 4, Model (iii) does not include any individual heterogeneity, whereas Model (iv) includes scale coefficients and Model (v) includes random coefficients. Model (vi) includes both random and scale coefficients. Indicated numbers are frequency and volume shares of each payment method.

cannot give good fitness for micro-moments; in particular, the model cannot capture the substitution between cash and debit card. Table 8 shows the fitness of the model conditioned on merchants' acceptance. In the top panel, 'Merchants Accepting Cash and Credit,' we calculate the frequency and value share where merchants accept only cash and credit cards. Unfortunately, all models predict higher numbers for cash usage. On the other hand, in the bottom panel, 'Merchants Accepting Cash and Debit,' as we include more unobserved heterogeneity, these models capture the substitution between cash and debit cards quite well. For example, cash usage is about $64.22 \%$ in the data, and Model (vi) predicts 61.91\% for 'Merchants Accepting Cash and Debit.' These observations allow us to proceed to the counterfactual simulations using these estimated models and parameters.

\subsection{Simulation Results}

Using the estimated model demonstrated above, we conduct a policy simulation where all merchants accept any payment method regardless of transaction values. This question is motivated by policy makers' recent interest in understanding the demand for cash under such a counterfactual scenario, as many recent studies reveal that cash is still a dominant payment method for small-value transactions. 
TABle 8: Model Fit - By Merchants' Acceptance

\begin{tabular}{|c|c|c|c|c|c|}
\hline & \multirow[b]{2}{*}{ Data } & \multicolumn{4}{|c|}{ Model Prediction } \\
\hline & & Model (iii) & Model (iv) & Model (v) & Model (vi) \\
\hline \multicolumn{6}{|c|}{ Merchants Accepting Cash and Credit } \\
\hline \multicolumn{6}{|c|}{ Frequency Share } \\
\hline Cash & $66.36 \%$ & $73.53 \%$ & $74.92 \%$ & $74.97 \%$ & $74.86 \%$ \\
\hline Credit & $33.64 \%$ & $26.47 \%$ & $25.08 \%$ & $25.03 \%$ & $25.14 \%$ \\
\hline \multicolumn{6}{|c|}{ Value Share } \\
\hline Cash & $26.81 \%$ & $40.84 \%$ & $43.60 \%$ & $44.22 \%$ & $41.99 \%$ \\
\hline Credit & $73.19 \%$ & $59.16 \%$ & $56.40 \%$ & $55.78 \%$ & $58.01 \%$ \\
\hline \multicolumn{6}{|c|}{ Merchants Accepting Cash and Debit } \\
\hline \multicolumn{6}{|c|}{ Frequency Share } \\
\hline Cash & $64.22 \%$ & $59.81 \%$ & $60.70 \%$ & $62.53 \%$ & $61.91 \%$ \\
\hline Debit & $35.78 \%$ & $40.19 \%$ & $39.30 \%$ & $37.47 \%$ & $38.09 \%$ \\
\hline \multicolumn{6}{|c|}{ Value Share } \\
\hline Cash & $37.39 \%$ & $33.97 \%$ & $37.59 \%$ & $40.90 \%$ & $39.57 \%$ \\
\hline Debit & $62.61 \%$ & $66.03 \%$ & $62.41 \%$ & $59.10 \%$ & $60.43 \%$ \\
\hline
\end{tabular}

Note: As indicated in Table 4, Model (iii) does not include any individual heterogeneity, whereas Model (iv) includes scale coefficients and Model (v) includes random coefficients. Model (vi) includes both random and scale coefficients. Indicated numbers are frequency and volume shares of each payment method.

Simulation Details We hypothetically allow consumers to use their credit and debit cards without incurring any additional costs for using them, even though, in reality, they sometimes would not be able to use their cards. We also assume that all consumers can use debit and credit cards. For those consumers who do not have any credit cards, we hypothetically give them a credit card with zero rewards and the lowest credit limit, i.e., $\$ 500$. For those consumers who do not have any debit cards, we hypothetically give them a debit card so that they can use their debit cards for any transaction. To conduct this counterfactual experiment, we use the fact that the estimator satisfies asymptotic normality. Thus, we prepare $r=2,000$ sets of normal random draws of $\boldsymbol{\nu}^{r}$ and construct $\boldsymbol{\theta}^{r}=\hat{\boldsymbol{\theta}}+\hat{\boldsymbol{\sigma}} \boldsymbol{\nu}^{r}$, where $\hat{\boldsymbol{\theta}}$ and $\hat{\boldsymbol{\sigma}}$ denote the estimates and standard errors for the estimates. We also prepare the $r=2,000$ draws for each random coefficient and scale coefficient, $\left(\boldsymbol{\epsilon}^{r}, \boldsymbol{\eta}^{r}\right)$. Then, we simulate the choice probabilities for all methods of payment, whereas consumers' choice sets are restricted by merchants' acceptance in the estimation. Finally, we subtract the former predicted shares from the latter predicted 
shares. $^{20}$ Notice that we use the weight $w_{i}$ here, whereas we use the 'weighted' weight for showing the fitness of the models, as in Tables 7 and 8, i.e., the predicted shares are calculated via

$$
s_{j}^{C}=\sum_{i=1}^{N} \sum_{t=1}^{T_{i}}\left[\frac{1}{R} \sum_{r=1}^{R} w_{i} \mathrm{P}\left(y_{i j t}=1 \mid \boldsymbol{X}_{i j t}, \boldsymbol{\theta}^{r}, \boldsymbol{\epsilon}_{i}^{r}, \boldsymbol{\eta}_{i}^{r}\right)\right] .
$$

\subsubsection{Overall Effects}

Table 9 presents an overview of the simulation results. First, in terms of the frequency, overall cash usage would decrease by 6.9 percentage points to 8.0 percentage points, depending on the model, whereas the transaction amount of cash usage would decrease by 6.9 percentage points to 7.9 percentage points. The most important observation here is that the dominance of cash usage in small-value transactions is driven by consumers - consumers would not decrease their use of cash even if merchants accepted credit and debit cards. Although one might think this change is relatively small, this small overall effect is driven by the fact that many people use cash for small-value transactions even if these merchants accept cards, as indicated in Figure 6. The right panel of Figure 6 shows the frequencies of three methods of payment by transaction values only transactions that accepted all three method of payment, whereas the left panel includes all transactions.

There is one more important remark about Table 9. The table indicates the importance of the unobserved individual heterogeneity. The decrease in cash usage is smaller in Model (iii), which does not have any unobserved heterogeneity, than in other models that have heterogeneity. This result implies that Model (iii) fails to capture the behavior of debit users and credit users. Those committed users should be likely to use their cards under the counterfactual situation where all merchants accept cards, and Models (iv) through (vi) capture such patterns. However, Model (iii) does not have any individual-level heterogeneity and cannot capture such patterns.

\footnotetext{
${ }^{20}$ As indicated in Table 7, the predictions from the models cannot predict the data shares exactly. Thus, we calculate the difference between predicted shares under the current choice sets and under the counterfactual choice sets.
} 
TABLE 9: Simulation results for overall effects

\begin{tabular}{lccccc}
\hline \hline & & \multicolumn{4}{c}{ Model Prediction } \\
\cline { 3 - 6 } & Data & Model (iii) & Model (iv) & Model (v) & Model (vi) \\
\hline Frequency Share & & & & & \\
$\quad$ Cash & $56.99 \%$ & $-6.86 \%$ & $-7.58 \%$ & $-7.98 \%$ & $-7.70 \%$ \\
$\quad$ Credit & $18.91 \%$ & $3.69 \%$ & $4.17 \%$ & $4.76 \%$ & $4.38 \%$ \\
$\quad$ Debit & $24.10 \%$ & $3.18 \%$ & $3.41 \%$ & $3.22 \%$ & $3.32 \%$ \\
Value Share & & & & & \\
$\quad$ Cash & $30.06 \%$ & $-6.93 \%$ & $-7.55 \%$ & $-7.86 \%$ & $-7.53 \%$ \\
Credit & $36.01 \%$ & $4.34 \%$ & $5.57 \%$ & $5.87 \%$ & $5.21 \%$ \\
$\quad$ Debit & $33.93 \%$ & $2.58 \%$ & $1.98 \%$ & $1.99 \%$ & $2.33 \%$ \\
\hline \hline
\end{tabular}

Note: The displayed numbers in 'Model Prediction' columns are percentage point changes which are calculated as the difference between the predicted market share under the current choice sets and the predicted market share under the counterfactual choice sets.

\subsubsection{Detailed Effects}

Acceptance Types In Table 10, we show the models' prediction depending on the merchants acceptance. For example, in the top panel, 'Merchants Accepting Cash,' we calculate the percentage point change only for the merchants that currently accept only cash. For those transactions, the decrease in cash usage is huge, since many consumers would use credit and debit cards if merchants accepted cards. Thus, cash share would decrease by about 34 percentage points.

On the other hand, in the next two panels 'Merchants Accepting Cash and Credit' and 'Merchants Accepting Cash and Debit,' we can see much smaller changes. This is partially because merchants have already accepted cash and one electronic payment method. However, here, we can see the clear difference between Model (iii) and Model (vi). For example, Model (iii) predicts decreases of about 11.49 percentage points and 5.21 percentage points for cash and credit card share, whereas Model (vi) predicts decreases of about 13.96 percentage points and 3.61 percentage points for cash and credit card. This is because, in this case, we should expect that the most substitutions would happen from cash share to debit card share, with a slight decrease in credit cards share. Some mixed users, who wanted to use debit cards but could not because they were not accepted and used credit cards instead, would use debit cards, which leads to a small decrease in credit usage. However, the number of such mixed users should 
Figure 6: Method of Payment Choices by Acceptance
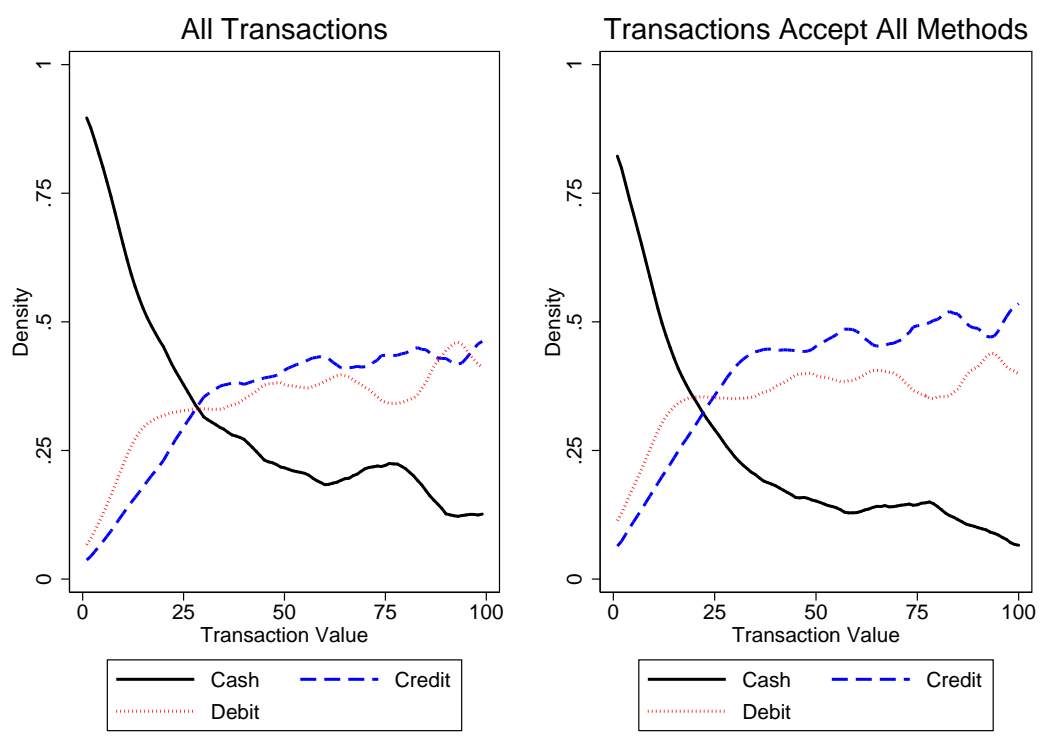

Note: The left panel shows the three methods' frequency by transaction values for all transac-
tions (it is identical to Figure 1), whereas the right panel shows the three methods' frequency for transactions that accept all three methods.

be small and the effect should be limited. Therefore, we should expect most of the decrease in cash and the Model (vi) support our intuitions. The same thing happens for merchants that accept cash and debit cards.

Last, in the bottom panel, which shows merchants accepting every payment method already, the changes are very limited for any payment method and any model. This is because the merchants have already accepted any payment method and consumers choose their method of payment optimally. Therefore, we should not see huge changes here and the results validate the models.

Transaction Values In Table 11, we show the models' prediction depending on the transaction values. For instance, in the top panel, 'Less than $\$ 10$,' we calculate the percentage point change only for the transactions which are less than $\$ 10$. Though the market share of cash in the data is quite huge for less than $\$ 10$ transactions, the percentage change is small. On the other hand, transactions between $\$ 10$ and $\$ 25$, the decreases are about 10 percentage points, even though the original market share is much smaller than less than $\$ 10$ transactions. Therefore, these observations support that the results - cash usage in small-value transactions is driven by consumers - is 
TABle 10: Simulation Results - By Merchants' Acceptance

\begin{tabular}{|c|c|c|c|c|c|}
\hline & \multirow[b]{2}{*}{ Data } & \multicolumn{4}{|c|}{ Model Prediction } \\
\hline & & Model (iii) & Model (iv) & Model (v) & Model (vi) \\
\hline \multicolumn{6}{|c|}{ Merchants Accepting Cash } \\
\hline \multicolumn{6}{|c|}{ Frequency Share } \\
\hline Cash & $100.00 \%$ & $-32.85 \%$ & $-34.64 \%$ & $-34.39 \%$ & $-34.31 \%$ \\
\hline Credit & $0.00 \%$ & $14.51 \%$ & $15.36 \%$ & $16.49 \%$ & $15.87 \%$ \\
\hline Debit & $0.00 \%$ & $18.35 \%$ & $19.28 \%$ & $17.90 \%$ & $18.45 \%$ \\
\hline \multicolumn{6}{|c|}{ Value Share } \\
\hline Cash & $100.00 \%$ & $-67.66 \%$ & $-66.77 \%$ & $-67.71 \%$ & $-67.70 \%$ \\
\hline Credit & $0.00 \%$ & $33.08 \%$ & $34.57 \%$ & $35.96 \%$ & $34.64 \%$ \\
\hline Debit & $0.00 \%$ & $34.58 \%$ & $32.20 \%$ & $31.74 \%$ & $33.06 \%$ \\
\hline \multicolumn{6}{|c|}{ Merchants Accepting Cash and Credit } \\
\hline \multicolumn{6}{|c|}{ Frequency Share } \\
\hline Cash & $68.55 \%$ & $-11.49 \%$ & $-15.27 \%$ & $-14.38 \%$ & $-13.96 \%$ \\
\hline Credit & $31.45 \%$ & $-5.21 \%$ & $-3.81 \%$ & $-2.68 \%$ & $-3.61 \%$ \\
\hline Debit & $0.00 \%$ & $16.69 \%$ & $19.08 \%$ & $17.06 \%$ & $17.58 \%$ \\
\hline \multicolumn{6}{|c|}{ Value Share } \\
\hline Cash & $28.88 \%$ & $-7.61 \%$ & $-13.38 \%$ & $-12.38 \%$ & $-9.61 \%$ \\
\hline Credit & $71.12 \%$ & $-12.86 \%$ & $-10.17 \%$ & $-9.91 \%$ & $-12.18 \%$ \\
\hline Debit & $0.00 \%$ & $20.47 \%$ & $23.55 \%$ & $22.29 \%$ & $21.79 \%$ \\
\hline \multicolumn{6}{|c|}{ Merchants Accepting Cash and Debit } \\
\hline \multicolumn{6}{|c|}{ Frequency Share } \\
\hline Cash & $65.42 \%$ & $-4.80 \%$ & $-6.67 \%$ & $-7.39 \%$ & $-6.92 \%$ \\
\hline Credit & $0.00 \%$ & $8.55 \%$ & $10.23 \%$ & $10.60 \%$ & $10.09 \%$ \\
\hline Debit & $34.58 \%$ & $-3.76 \%$ & $-3.55 \%$ & $-3.21 \%$ & $-3.17 \%$ \\
\hline \multicolumn{6}{|c|}{ Value Share } \\
\hline Cash & $39.74 \%$ & $-4.59 \%$ & $-8.82 \%$ & $-11.01 \%$ & $-10.08 \%$ \\
\hline Credit & $0.00 \%$ & $14.64 \%$ & $20.58 \%$ & $22.20 \%$ & $20.67 \%$ \\
\hline Debit & $60.26 \%$ & $-10.05 \%$ & $-11.76 \%$ & $-11.20 \%$ & $-10.59 \%$ \\
\hline \multicolumn{6}{|c|}{ Merchants Accepting Every Method } \\
\hline \multicolumn{6}{|c|}{ Frequency Share } \\
\hline Cash & $42.24 \%$ & $-0.23 \%$ & $-0.11 \%$ & $-0.69 \%$ & $-0.41 \%$ \\
\hline Credit & $28.70 \%$ & $-0.04 \%$ & $-0.07 \%$ & $0.41 \%$ & $0.17 \%$ \\
\hline Debit & $29.05 \%$ & $0.26 \%$ & $0.18 \%$ & $0.27 \%$ & $0.24 \%$ \\
\hline \multicolumn{6}{|c|}{ Value Share } \\
\hline Cash & $19.43 \%$ & $-0.01 \%$ & $0.19 \%$ & $0.32 \%$ & $0.46 \%$ \\
\hline Credit & $47.01 \%$ & $-0.77 \%$ & $-0.67 \%$ & $-0.80 \%$ & $-1.13 \%$ \\
\hline Debit & $33.56 \%$ & $0.78 \%$ & $0.48 \%$ & $0.48 \%$ & $0.67 \%$ \\
\hline
\end{tabular}

Note: The displayed numbers in 'Model Prediction' columns are percentage point changes which are calculated as the difference between the predicted market share under the current choice sets and the predicted market share under the counterfactual choice sets. 
robust.

TABLE 11: Simulation Results - By Transaction Values

\begin{tabular}{|c|c|c|c|c|c|}
\hline & \multirow[b]{2}{*}{ Data } & \multicolumn{4}{|c|}{ Model Prediction } \\
\hline & & Model (iii) & Model (iv) & Model (v) & Model (vi) \\
\hline \multicolumn{6}{|c|}{ Less Than $\$ 10$} \\
\hline \multicolumn{6}{|c|}{ Frequency Share } \\
\hline Cash & $85.44 \%$ & $-6.19 \%$ & $-7.29 \%$ & $-8.11 \%$ & $-7.46 \%$ \\
\hline Credit & $4.68 \%$ & $2.87 \%$ & $3.53 \%$ & $4.32 \%$ & $3.79 \%$ \\
\hline Debit & $9.88 \%$ & $3.33 \%$ & $3.76 \%$ & $3.79 \%$ & $3.68 \%$ \\
\hline \multicolumn{6}{|c|}{ Value Share } \\
\hline Cash & $79.04 \%$ & $-6.31 \%$ & $-6.96 \%$ & $-7.85 \%$ & $-7.34 \%$ \\
\hline Credit & $7.05 \%$ & $3.21 \%$ & $3.62 \%$ & $4.48 \%$ & $3.96 \%$ \\
\hline Debit & $13.91 \%$ & $3.10 \%$ & $3.33 \%$ & $3.38 \%$ & $3.38 \%$ \\
\hline \multicolumn{6}{|c|}{ Between $\$ 10$ and $\$ 25$} \\
\hline \multicolumn{6}{|c|}{ Frequency Share } \\
\hline Cash & $52.34 \%$ & $-9.04 \%$ & $-9.53 \%$ & $-9.73 \%$ & $-9.77 \%$ \\
\hline Credit & $17.20 \%$ & $4.90 \%$ & $4.45 \%$ & $5.57 \%$ & $5.32 \%$ \\
\hline Debit & $30.46 \%$ & $4.14 \%$ & $5.08 \%$ & $4.16 \%$ & $4.45 \%$ \\
\hline \multicolumn{6}{|c|}{ Value Share } \\
\hline Cash & $50.65 \%$ & $-8.36 \%$ & $-8.76 \%$ & $-8.98 \%$ & $-9.02 \%$ \\
\hline Credit & $18.00 \%$ & $4.58 \%$ & $4.21 \%$ & $5.23 \%$ & $5.01 \%$ \\
\hline Debit & $31.34 \%$ & $3.78 \%$ & $4.55 \%$ & $3.75 \%$ & $4.01 \%$ \\
\hline \multicolumn{6}{|c|}{ More than $\$ 25$} \\
\hline \multicolumn{6}{|c|}{ Frequency Share } \\
\hline Cash & $26.95 \%$ & $-6.00 \%$ & $-6.45 \%$ & $-6.52 \%$ & $-6.42 \%$ \\
\hline Credit & $37.00 \%$ & $3.73 \%$ & $4.71 \%$ & $4.68 \%$ & $4.37 \%$ \\
\hline Debit & $36.05 \%$ & $2.27 \%$ & $1.74 \%$ & $1.84 \%$ & $2.04 \%$ \\
\hline \multicolumn{6}{|c|}{ Value Share } \\
\hline Cash & $22.49 \%$ & $-6.72 \%$ & $-7.38 \%$ & $-7.66 \%$ & $-7.28 \%$ \\
\hline Credit & $41.55 \%$ & $4.39 \%$ & $5.97 \%$ & $6.10 \%$ & $5.34 \%$ \\
\hline Debit & $35.96 \%$ & $2.33 \%$ & $1.40 \%$ & $1.56 \%$ & $1.94 \%$ \\
\hline
\end{tabular}

Note: The displayed numbers in 'Model Prediction' columns are percentage point changes which are calculated as the difference between the predicted market share under the current choice sets and the predicted market share under the counterfactual choice sets.

\subsection{Some Discussions}

As mentioned in Sections 2 and 3, there may exist some potential endogenity problems in the estimation and the counterfactual simulation. We summarize and discuss them briefly in this section. 
Measurement Errors in Perceived Acceptance and Endogeneity First, we use the reported perceived acceptance data, which may have measurement errors, since consumers tend to go to merchants that are likely to accept their preferred method of payment and report inaccurately about acceptance of their non-preferred method of payment. Unfortunately, in these data, we cannot verify whether their reported acceptances are correct. However, as in Table 3, we do have a number of observations where some merchants accept only credit cards or debit cards, which validate the accuracy of data. Thus, this paper uses their reported perceived acceptance without any imputation.

This perceived acceptance might create a bias in the counterfactual experiment. In particular, when we measure the welfare gain in the counterfactual experiment, we might underestimate it. As indicated in Table 3, currently many consumers choose shops that accept their preferred method of payment, e.g., credit users are more likely to go to merchants that accept credit cards. However, under the counterfactual scenario, they would not have to choose merchants by their acceptance. Since this paper does not measure the welfare gain/loss, this problem cannot be a major concern.

There might be another concern of a selection problem of credit cards. As Arango, Huynh, and Sabetti (2011) investigate, those consumers who tend to use their credit cards are likely to have good reward programs on their cards. Under the couterfactual scenario, some cash users and debit users might obtain new credit cards which have better reward programs and start using them. This model cannot capture such behavior, as their credit card selection behavior is not explicitly modelled. Therefore, the results indicated above should be interpret as a short term effect where consumers continue to use the same credit cards.

Supply Effects and Externalities Finally, this paper cannot capture any externalities in the counterfactual simulation. For example, as a result of forcing merchants to accept electronic cards, merchants might get used to processing cards and therefore the speed of settlement for these cards would be faster than before. Observing this faster settlement for cards, consumers might use cards more frequently. This is one of the externalities for forcing merchants to accept cards.

Moreover, the models do not take into account merchants' behavior nor the behav- 
ior of credit and debit card network providers. They might potentially change their behavior, in particular, they might charge higher interchange and surcharge fees to exploit their monopolistic or oligopolistic market power. To fully predict what would happen if merchants were forced to accept cards, we need to take into account their behavior.

\section{Conclusion}

This paper investigates consumers' method of payment choices. To exploit the individual heterogeneity in payment choice, we use a generalized multinomial logit model, taking advantage of the data where we can observe multiple transactions for each individual. Moreover, "perceived" acceptance, which partially gives supply-side information, enables us to separately identify demand-side factors from the supply-side factors. Estimation results confirm that such unobserved heterogeneity in method of payment choice is indeed significant both statistically and economically. Using the estimated model, we conduct the counterfactual simulation where all merchants accept cards regardless of transaction values. Simulation results show that cash usage would indeed decrease but the magnitude is quite limited: cash usage decreases at most about 8 percentage points in frequency share. The implication of this result is that current cash usage is driven by demand-side factors - consumers prefer using cash, in particular, for small-value transactions.

As this paper focuses on consumer's method of payment choice, we abstract from

other potential issues listed in Section 4. Considering issues, e.g., competition among network providers or measurement error in choice sets, would be an interesting extension for future research.

\section{References}

Arango, C., D. Hogg, And A. Lee (2012): "Why Is Cash (Still) So Entrenched? Insights from the Bank of Canada's 2009 Methods-of-Payment Survey," Bank of Canada Discussion Paper, 2012-2. 
Arango, C., K. P. Huynh, and L. Sabetti (2011): "How Do You Pay? The Role of Incentives at the Point-of-Sale," Bank of Canada Working Paper 2011-23.

Arango, C., And A. Welte (2012): "Bank of Canada 2009 Methods of Payment Survey: Methodology and Key Results," Bank of Canada website (forthcoming).

Bolt, W., N. Jonker, and C. van RenselaAR (2010): "Incentives at the Counter: An Empirical Analysis of Surcharging Card Payments and Payment Behaviour in the Netherlands," Journal of Banking \& Finance, 34(8), 1738-1744.

Borzekowski, R., E. K. Kiser, and S. Ahmed (2008): "Consumers' Use of Debit Cards: Patterns, Preferences, and Price Response," Journal of Money, Credit and Banking, 40(1), 149-172.

Briesch, R. A., P. K. Chintaguanta, and R. L. Matzkin (2010): "Nonparametric Discrete Choice Models with Unobserved Heterogeneity," Journal of Business \& Economic Statistics, 28(2), 291-307.

Briesch, R. A., P. K. Chintagunta, and R. L. Matzkin (2002): "Semiparametric Estimation of Brand Choice Behevior," Journal of the American Statistical Association, 97, 973-982.

Ching, A. T., and F. Hayashi (2010): "Payment Card Rewards Programs and Consumer Payment Choice," Journal of Banking \& Finance, 34, 1773-1787.

Fiebig, D. G., M. P. Keane, J. Louviere, and N. Wasi (2010): "The Generalized Multinomial Logit Model: Accounting for Scale and Coefficient Heterogeneity," Marketing Science, 29(3), 393-421.

Fox, J. T. (2007): "Semiparametric Estimation of Multinomial Discrete-Choice Models Using a Subset of Choices," RAND Journal of Economics, 38(4), 1002-1019.

Fox, J. T., K. Il Kim, S. P. Ryan, and P. Bajari (2012): "The Random Coefficients Logit Model is Identified," Journal of Econometrics, 166, 204-212.

Harris, K. M., and M. P. Keane (1999): "A Model of Health Plan Choice: Inferring Preferences and Perceptions from a Combination of Revealed Preference and Attitudinal Data," Journal of Econometrics, 89, 131-157. 
Humphrey, D. B. (2010): "Retail Payments: New Contributions, Empirical Results, and Unanswered Questions," Journal of Banking \&3 Finance, 34(8), 1729-1737.

KleE, E. (2008): "How People Pay: Evidence from Grocery Store Data," Journal of Monetary Economics, 55(3), 526-541.

Lancaster, T. (2000): "The Incidental Parameter Problem since 1948," Journal of Econometrics, 95, 391-413.

Manski, C. F. (1975): "Maximum Score Estimation of the Stochastic Utility Model of Choice," Journal of Econometrics, 3(3), 205-228.

Neyman, J., And E. L. Scott (1948): "Consistent Estimates Based on Partially Consistent Observations," Econometrica, 16(1), 1-32.

Revelt, D., and K. Train (1998): "Mixed Logit With Repeated Choices: Households' Choices of Appliance Efficiency Level," Review of Economics and Statistics, 80(4), 647-657.

Rochet, J.-C., and J. Tirole (2002): "Cooperation among Competitors: Some Economics of Payment Card Associations," RAND Journal of Economics, 33(4), 549-570.

Rochet, J.-C., And J. Wright (2010): "Credit Card Interchange Fees," Journal of Banking $\&$ Finance, 34(8), 1788-1797.

Rysman, M. (2007): "An Empirical Analysis of Payment Card Usage," Journal of Industrial Economics, 55(1), 1-36.

Schuh, S., and J. Stavins (2010): "Why Are (Some) Consumers (Finally) Writing Fewer Checks? The Role of Payment Characteristics," Journal of Banking 8 Finance, 34, 1745-1758.

Shy, O., and Z. Wang (2011): "Why Do Payment Card Networks Charge Proportional Fees?," American Economic Review, 101, 1575-1590.

Sieber, G. (2011): "The Effect of Credit Card Reward on Method of Payment," Master's thesis, Department of Economics, University of Mannheim. 
Simon, J., K. Simith, and T. West (2010): "Price Incentives and Consumer Payment Behaviour," Journal of Banking \& Finance, 34(8), 1759-1772.

Train, K. E. (1998): "Recreation Demand Models with Taste Differences Over People," Land Economics, 74(2), 230-239.

Wright, R., and I. A. Telyukova (2008): "A Model of Monetary and Credit, with Application to the Credit Card Debt Puzzle," Review of Economic Studies, 75(2), 629-647.

Zinman, J. (2009): "Debit or Credit?," Journal of Banking E3 Finance, 33(2), 358-366.

\section{Appendix: Sample Construction}

Originally, the number of individuals who completed the diary survey instrument (DSI) is 3,253 . To construct the estimation samples, we first drop 348 individuals who did not answer some attitudinal questions or who were missing some important demographic variables. These operations leave 2,905 individuals with 16,135 transactions.

As a second step, we drop some transactions if missing transaction values $(1,674$ transactions), if missing decision (54 transactions), if using multiple transaction methods (161 transactions), if using checks or store-value cards (300 transactions), if missing perceived acceptance (4,111 transactions), if inconsistent with decision and choice sets (299 transactions), if unable to use cash (208 transactions), if transaction value is more than $\$ 300$ (103 transactions). These operations leave 2,336 individuals with 9,220 transactions. ${ }^{21}$

Along the process, the biggest drop has occurred as a result of missing perceived acceptance. One potential concern is that those who do not report the perceived acceptance might be correlated with transaction values, which is the most important determinant in payment choices economically and statistically. As we can easily imagine, for small-value transactions, respondents might not know their acceptance and might more likely answer 'I do not know.' If this is true, this process would create

\footnotetext{
${ }^{21} 569$ respondents have been dropped during these operations, as they have zero transactions which can be used for the estimation.
} 
Figure 7: Transaction Value Distributions

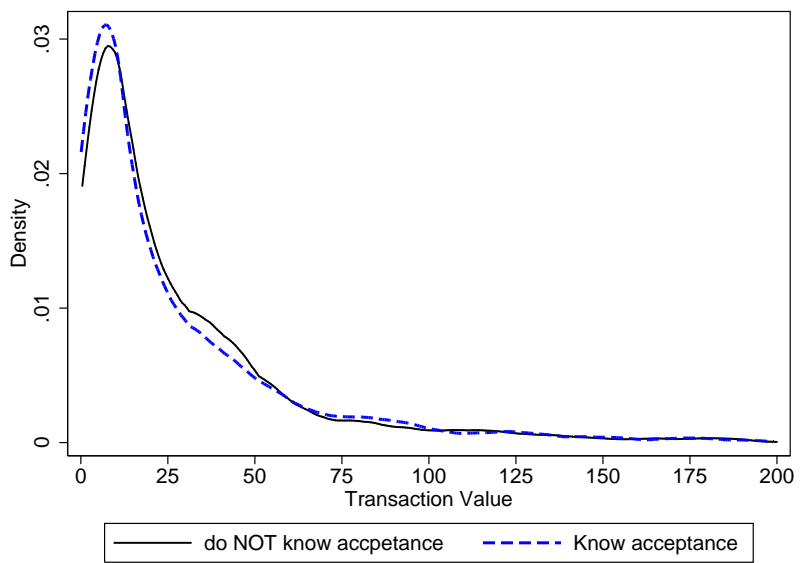

Note: The black solid line shows the distribution of transaction values when consumers answer 'I know the acceptance' and the blue dotted line shows the distribution of transaction values when consumers report 'I do NOT know the acceptance,' which we drop from our estimation sample.

some problems. However, as Figure 7 indicates, the distributions of transaction values look similar. We might be able to impute the acceptance based on transaction values, the number of cashiers at each merchant, and shopping type. However, we will not take this approach as this perceived acceptance is one of the key variables and it seems there is no systematic correlation at least for transaction values.

Finally, for identification purposes, we drop 884 individuals with 1,312 transactions, since they had only one or two shopping records. This final operation yields 1,452 individuals with 7,908 transactions. Again, we also show two distributions for transaction values, which stay in the sample and are dropped from the sample in Figure 8. These two kernel density estimates suggest that both distributions are similar and we can estimate the models with 1,452 individuals without any problems, since they are representative. 
Figure 8: Transaction Value Distributions

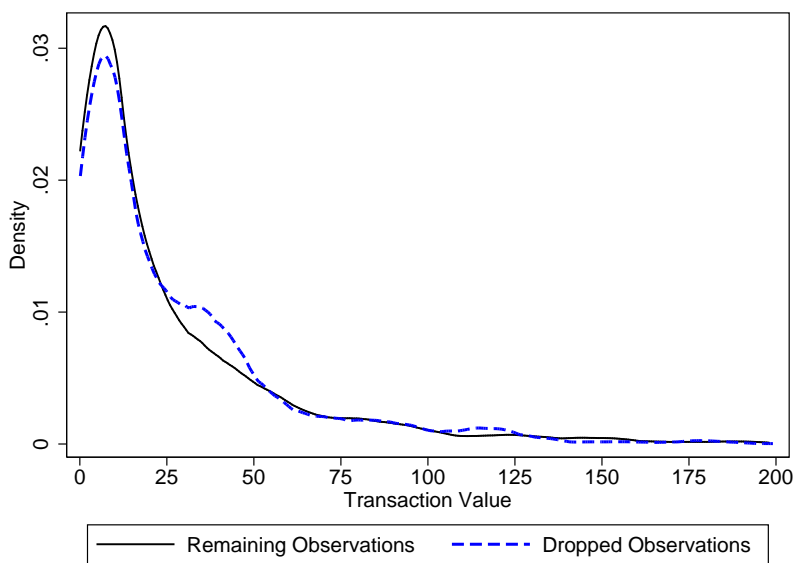

Note: The black solid line shows the distribution of transaction values that we use for this paper and the blue dotted line shows the distribution of transaction values that we drop from our estimation samples. 